\title{
Silica nanoparticles induce lung inflammation in mice via ROS/PARP/TRPM2 signaling-mediated lysosome impairment and autophagy dysfunction
}

Mingxiang Wang ${ }^{1 \dagger}$, Jin $\mathrm{Li}^{1+}$, Shunni Dong ${ }^{2}$, Xiaobo Cai ${ }^{1,3}$, Aili Simaiti ${ }^{1}$, Xin Yang ${ }^{1}$, Xinqiang Zhu ${ }^{1,4}$, Jianhong Luo ${ }^{5}$, Lin-Hua Jiang ${ }^{6,7}$, Binyang Du ${ }^{2^{*}}$, Peilin Yu ${ }^{1^{*}}$ and Wei Yang ${ }^{3^{*}}$ (D)

\begin{abstract}
Background: Wide applications of nanoparticles (NPs) have raised increasing concerns about safety to humans. Oxidative stress and inflammation are extensively investigated as mechanisms for NPs-induced toxicity. Autophagy and lysosomal dysfunction are emerging molecular mechanisms. Inhalation is one of the main pathways of exposing humans to NPs, which has been reported to induce severe pulmonary inflammation. However, the underlying mechanisms and, more specifically, the interplays of above-mentioned mechanisms in NPs-induced pulmonary inflammation are still largely obscure. Considered that NPs exposure in modern society is often unavoidable, it is highly desirable to develop effective strategies that could help to prevent nanomaterials-induced pulmonary inflammation.
\end{abstract}

Results: Pulmonary inflammation induced by intratracheal instillation of silica nanoparticles (SiNPs) in C57BL/6 mice was prevented by PJ34, a poly (ADP-ribose) polymerase (PARP) inhibitor. In human lung bronchial epithelial (BEAS2B) cells, exposure to SiNPs reduced cell viability, and induced ROS generation, impairment in lysosome function and autophagic flux. Inhibition of ROS generation, PARP and TRPM2 channel suppressed SiNPs-induced lysosome impairment and autophagy dysfunction and consequent inflammatory responses. Consistently, SiNPs-induced pulmonary inflammation was prevented in TRPM2 deficient mice.

(Continued on next page)

\footnotetext{
*Correspondence: duby@zju.edu.cn; yupeilin@zju.edu.cn; yangwei@zju.edu.cn

${ }^{\dagger}$ Mingxiang Wang and Jin Li contributed equally to this work.

${ }^{2}$ MOE Key Laboratory of Macromolecular Synthesis and Functionalization,

Department of Polymer Science \& Engineering, Zhejiang University,

Hangzhou, China

'Department of Toxicology, and Department of Medical Oncology of Second

Affiliated Hospital, Zhejiang University School of Medicine, Hangzhou, P. R.

China

${ }^{3}$ Department of Biophysics, and Department of Neurosurgery of the First

Affiliated Hospital, Zhejiang University School of Medicine, Hangzhou, P. R.

China

Full list of author information is available at the end of the article
}

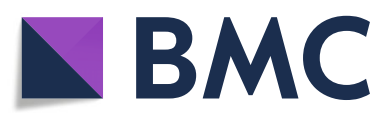

(- The Author(s). 2020 Open Access This article is licensed under a Creative Commons Attribution 4.0 International License, which permits use, sharing, adaptation, distribution and reproduction in any medium or format, as long as you give appropriate credit to the original author(s) and the source, provide a link to the Creative Commons licence, and indicate if changes were made. The images or other third party material in this article are included in the article's Creative Commons licence, unless indicated otherwise in a credit line to the material. If material is not included in the article's Creative Commons licence and your intended use is not permitted by statutory regulation or exceeds the permitted use, you will need to obtain permission directly from the copyright holder. To view a copy of this licence, visit http://creativecommons.org/licenses/by/4.0/. The Creative Commons Public Domain Dedication waiver (http://creativecommons.org/publicdomain/zero/1.0/) applies to the data made available in this article, unless otherwise stated in a credit line to the data. 
(Continued from previous page)

Conclusion: The ROS/PARP/TRPM2 signaling is critical in SiNPs-induced pulmonary inflammation, providing novel mechanistic insights into NPs-induced lung injury. Our study identifies TRPM2 channel as a new target for the development of preventive and therapeutic strategies to mitigate nanomaterials-induced lung inflammation.

Keywords: Nanoparticles, Pulmonary inflammation, ROS/PARP/TRPM2 signaling, Lysosomal impairment, Autophagy dysfunction

\section{Background}

Nanoparticles (NPs), by definition, have a size of less than $100 \mathrm{~nm}$ in at least one of their three dimensions. Growing use of nanomaterials-containing products, and increasing exposure of humans to NPs, have raised concerns about the safety of NPs to humans [1]. Inhalation is one of the main pathways of exposing humans to NPs, and it is generally thought that pulmonary inflammation is a common step [2] that initiates persistent inflammation and induces irreversible lung injury following exposure to NPs [3]. Silica nanoparticles (SiNPs) are amongst the well-accepted and most widely employed nanomaterials, and have applications in cosmetics, food additives, drug delivery, printer toner and paint [3]. Studies demonstrated exposure to SiNPs results in significant increases in the level of pro-inflammatory cytokines in bronchoalveolar lavage fluids (BALFs) and immune cell infiltration in vivo [4]. There is also evidence to support causative association of exposure to SiNPs with pulmonary fibrosis in animal models $[5,6]$. Besides, amorphous and crystal silica have been defined by the International Agency for Research on Cancer (IARC) as group 3 (inadequate evidence for carcinogenicity) and group 1 (sufficient evidence for the carcinogenicity to experimental animals and to humans) materials, respectively [7]. Thus, it is important to evaluate pulmonary inflammation induced by exposure to NPs, especially SiNPs, and better understand the underlying mechanisms.

It is well established that elevated reactive oxygen species (ROS) or oxidative stress has a crucial role in SiNPs-induced inflammation [1]. Besides, lysosome impairment and autophagy dysfunction are attracting growing attention for SiNPs-induced damages [8, 9]. Lysosomes contain diverse acidic hydrolases, such as cathepsins, and nanoparticles are reported to accumulate in the lysosomes by endocytosis and subsequently induce cathepsin-dependent inflammation [10]. Recent studies suggest that NPs induce activation of the NLRP3 inflammasome and generation of interleukin-1 $(\mathrm{IL}-1 \beta$ ) via lysosomal rupture and consequent release of cathepsins $[11,12]$. In addition, lysosome functions in the late stage of autophagy to maintain the integrity of autophagy flux, which associates to clearance of damaged organelles and aggregated proteins. SiNPs can induce autophagy mainly via oxidative stress-mediated upregulation of autophagy-related gene expression and differential regulation of the Akt/mTOR signaling [4]. Exposure to SiNPs at high doses or long exposure can also inhibit autophagosome degradation via blockage of autophagic flux [8], leading to disruption of cellular homeostasis [13]. Moreover, accumulating evidence suggests that the autophagy-lysosome pathway plays a key role in regulating systematic and local inflammatory responses [14]. Studies have reported many factors, including ROS generation, inflammation and autophagy dysfunction, are involved in mediating SiNPs-induced toxicity. However, a mechanistic understanding is still lacking and, more specifically, the interplay of ROS generation, lysosome impairment and autophagy dysfunction in SiNPs-induced inflammation. The chemical basis of SiNPs-induced toxicity is still largely obscure. Moreover, lung inflammation is an important target for preventing nanoparticleinduced diseases, and thus a clear understanding of nanoparticle-induced lung inflammation is the prerequisite for developing preventive and therapeutic strategies to alleviate the detrimental consequences of exposure to nanomaterials.

The transient receptor potential melastatin 2 (TRPM2) channel is an ADP-ribose (ADPR)-gated $\mathrm{Ca}^{2+}$-permeable non-selective cation channel and is expressed in many cell types [15]. TRPM2 channel is a key oxidative stress sensor, because ROS stimulates production of ADPR via the combined action of PARP and poly (ADP) glycohydrolase (PARG), and thereby activates the TRPM2 channel [16]. TRPM2-mediated $\mathrm{Ca}^{2+}$ signaling is known to impact physiologically important processes and functions, including autophagy and cell death [17, 18]. Our previous in vitro study showed that TRPM2 channel plays a role in mediating the detrimental effects of SiNPs on cell viability via promoting NADPH oxidasesmediated ROS production and altering the intracellular $\mathrm{Ca}^{2+}$ homeostasis [19]. However, whether such PARPmediated TRPM2 channel activation is associated with SiNPs-induced pulmonary inflammation in vivo and its specific molecular and cellular mechanisms remain unknown.

In the current study, we demonstrate that intratracheal (i.t.) instillation of SiNPs cause severe lung injury with pulmonary inflammation in mice. We show that 
exposure to SiNPs impaire lysosome function and autophagy process to induce inflammation in human lung bronchial epithelial (BEAS-2B) cells and further reveal the importance of the ROS/PARP/TRPM2 signaling in mediating SiNPs-induced lysosome impairment, autophagy dysfunction and inflammation. Consistently, transgenic deletion of the TRPM2 expression in mice completely eliminate SiNPs-induced pulmonary inflammation and lung injury, suggesting that TRPM2 channel plays a critical role in this process. We also confirm that the chemical basis of SiNPs-induced toxicity relates to the surface silanol groups, which suggests that modification of these surface groups is a strategy of reducing SiNPs-induced toxicity. Taken together, our study provides novel mechanistic insights into NPs-induced lung injury and identifies the TRPM2 channel as a new target for the development of preventive and therapeutic strategies to nanomaterials-induced lung inflammation.

\section{Results}

\section{Characterization of SiNPs}

SiNPs are well accepted as the most widely used nanoparticles. The morphology and size of commercially available SiNPs were characterized by transmission electron microscopy (TEM). SiNPs dispersed in distilled water by ultrasonication were spherical in shape with an average size of $16.75 \pm 3.38 \mathrm{~nm}$ (Additional file 1: Figure S1A and B). The surface area of SiNPs, determined by the BET method, was $156 \mathrm{~m}^{2} / \mathrm{g}$, which is similar with that reported by Zhang et al for fumed silica NPs (Additional file 1: Figure S1C) [20]. The hydrodynamic diameter of SiNPs in water and culture medium, determined by dynamic light scattering (DLS), was $155 \pm 10.8 \mathrm{~nm}$ and $178 \pm 9.61 \mathrm{~nm}$, respectively. The zeta value of SiNPs in distilled water and RPMI-1640 containing 10\% FBS was $-25.95 \pm 0.63 \mathrm{mV}$ and $-16.81 \pm 0.5 \mathrm{mV}$, respectively, suggesting SiNPs aggregation to some extent (Additional file 1: Figure S1D). Figure 1a showed the FTIR spectrum of SiNPs. A broad absorption peak centered at 3425 $\mathrm{cm}^{-1}$ was assigned to hydrogen-bonded vicinal silanols, and a small narrow peak at $3770 \mathrm{~cm}^{-1}$ in the enlarged spectrum in the range of $4700-3700 \mathrm{~cm}^{-1}$ was attributed to isolated silanols. Clearly, our SiNPs only contained a small fraction of isolated silanols on the surface. Thermogravimetric (TG) analysis indicated about $4.3 \%$ of weight loss after heating up to $800^{\circ} \mathrm{C}$ in air (Fig. 1b), accompanied with dehydroxylation of the silica surface via condensation reactions of adjacent surface silanoals and, additionally, a decrease in hydrogen-bonded vicinal silanols and an increase in isolated silanols [20]. The electron paramagnetic resonance (EPR) spectrum of SiNPs showed 1:2:2:1 quartet characteristic of $\mathrm{DMPO}-\mathrm{OH}^{*}$ in the presence but not in the absence of $\mathrm{H}_{2} \mathrm{O}_{2}$, indicating that SiNPs have an ability to generate hydroxyl radicals which can react with $\mathrm{H}_{2} \mathrm{O}_{2}$ to produce $\mathrm{OH}^{*}$ according to a Fenton-like reaction (Fig. 1c) [20, 21].

\section{Exposure to SiNPs induces lung inflammation in mice, depending on PARP activation.}

We firstly examined lung injury in wild-type (WT) C57BL/6 mice after i.t. instillation of SiNPs. Analysis of morphology and hematoxylin-eosin (H\&E) staining indicated that exposure to SiNPs resulted in significant tissue edema and infiltration of inflammatory cells (Fig. 2a). The levels of total protein and lactate dehydrogenase (LDH) in the BALFs, the widely-used markers of airway microvascular permeability and lung injury, respectively, were significantly elevated in SiNPs-exposed mice (Fig. 2b, c). The numbers of total cells, macrophages, neutrophils and lymphocytes were all increased upon SiNPs exposure (Fig. 2d-g). Among these parameters, increased neutrophil infiltration is one of the most sensitive
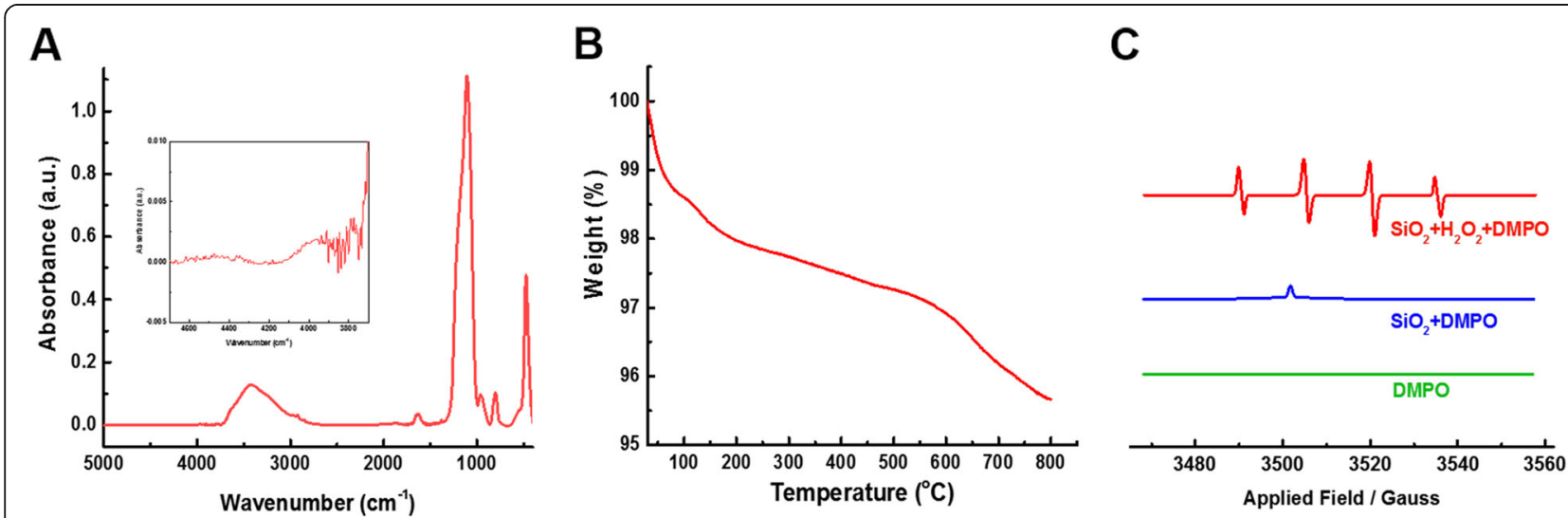

Fig. 1 Characterization of SiNPs in suspension. a The FTIR spectrum of SiNPs. Insert: The spectrum enlarged in the range of $4700-3700 \mathrm{~cm}^{-1}$. $\mathbf{b}$ TG analysis showing the weight loss of SiNPs during heating to $800^{\circ} \mathrm{C}$. C Derivative EPR data of SiNPs in the presence (red) or absence (blue) of $\mathrm{H}_{2} \mathrm{O}_{2}$, and DMPO without SiNPs as a negative control (green) 
A

Macroscopic images
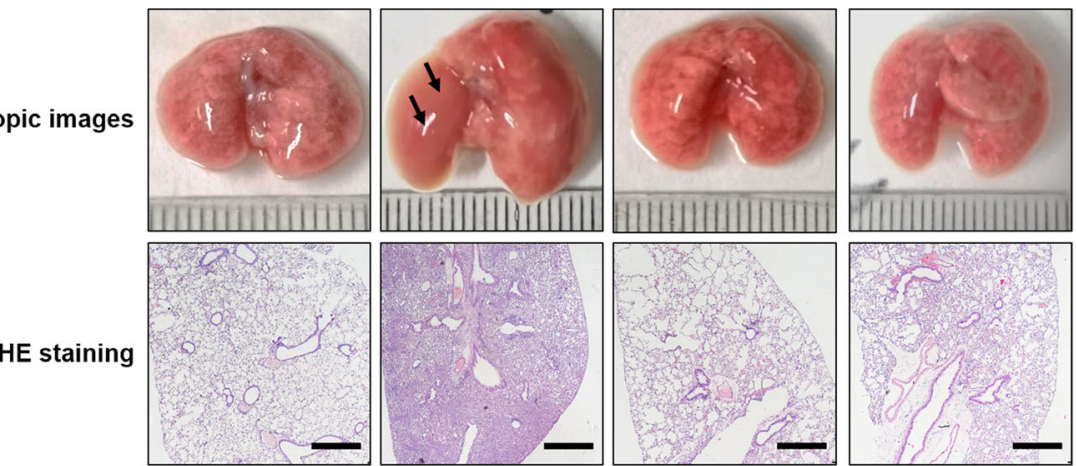

$\operatorname{SiNP}(10 \mathrm{mg} / \mathrm{kg})$

PJ34 (10 mg/kg/d)
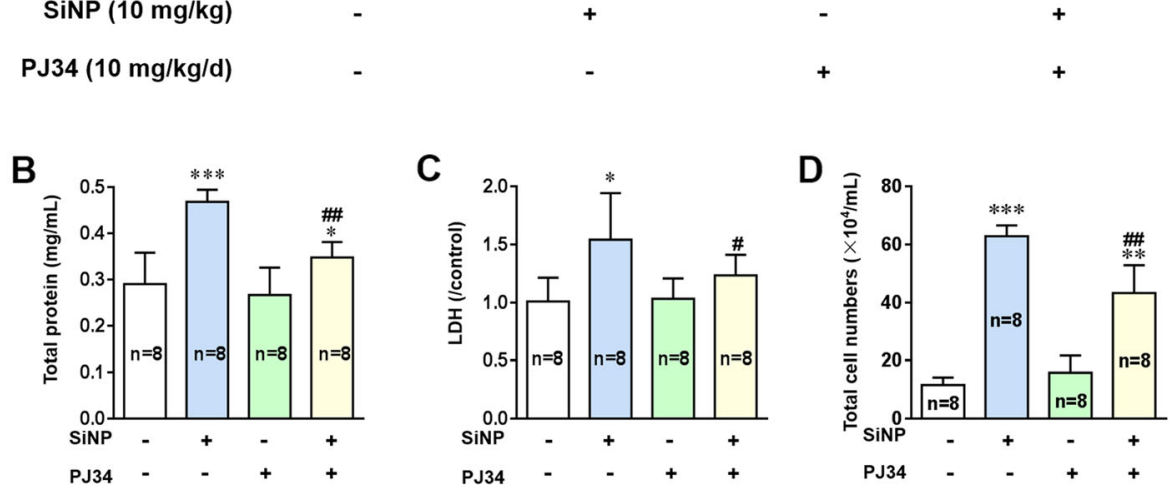

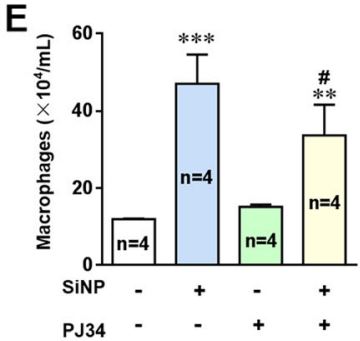

$\mathbf{F}$

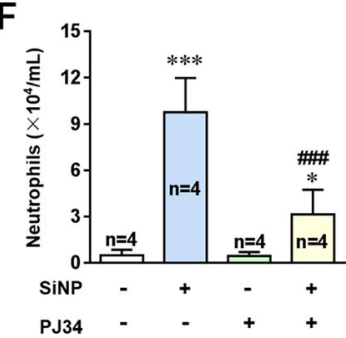

G
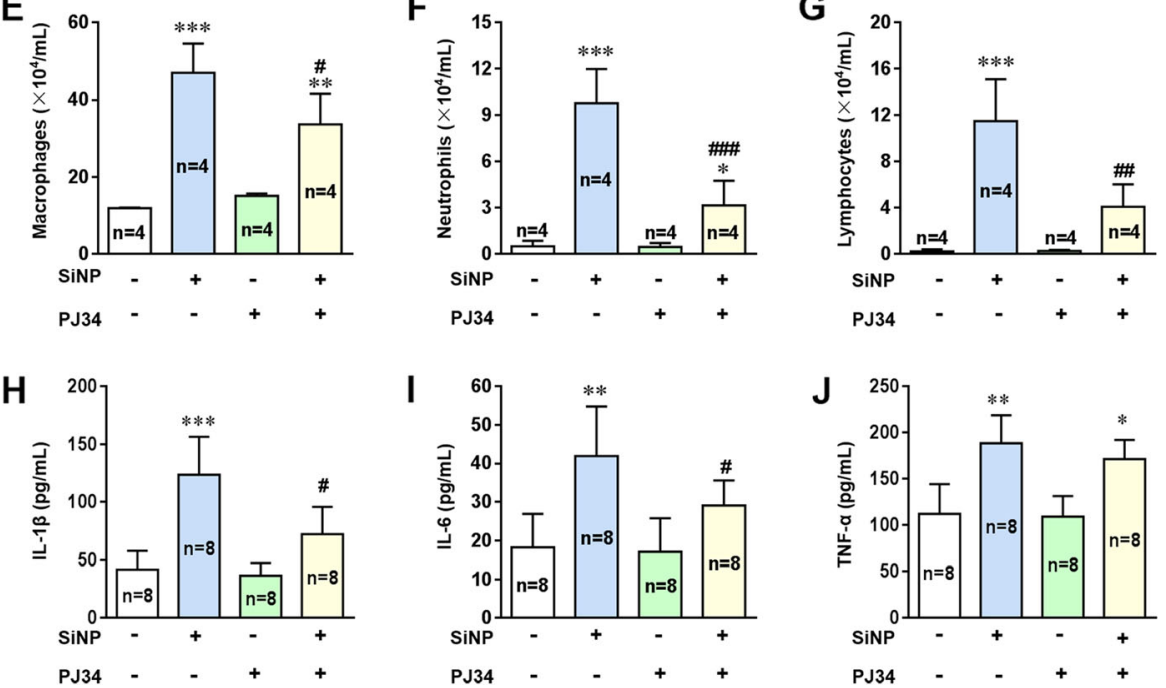

Fig. 2 Exposure to SiNPs induces severe lung injury and inflammation in mice, depending on PARP activation. a Representative lung histopathology on the 7th day in mice after treated with normal saline or SiNPs $(10 \mathrm{mg} / \mathrm{kg})$ in the absence or presence of PJ34 $(10 \mathrm{mg} / \mathrm{kg} / \mathrm{d})$. Black arrows indicate lung tissue edema. Scale bar $=500 \mu \mathrm{m}$. b-g Total protein concentrations (b), LDH release (c), total cells numbers (d), macrophages numbers $(\mathbf{e})$, neutrophils numbers $(\mathbf{f})$, and lymphocytes numbers $(\mathbf{g})$ in the BALFs of mice determined on the 7 th day after treated with normal saline or SiNPs $(10 \mathrm{mg} / \mathrm{kg})$ in the absence or presence of PJ34 $(10 \mathrm{mg} / \mathrm{kg} / \mathrm{d})$. $\mathbf{h}-\mathbf{j}$ The concentrations of IL-1 $\beta$ (h), IL-6 (i), and TNF-a (j) in the BALFs of mice under the same conditions as shown for $\mathbf{b}-\mathbf{g}$, as markers of local inflammation were measured by ELISA. ${ }^{*} P<0.05$, ${ }^{* *} P<0.01$, *** $P<0.001$ compared with the control group. ${ }^{\#} P<0.05$, ${ }^{\# \#} P<0.01$ compared with SiNPs-treated group

indicators for pulmonary inflammation, and a increase in the number of lymphocytes indicates an immune cell-mediated inflammatory response. We also used enzyme-linked immunosorbent assay (ELISA) to analyze the levels of key pro-inflammatory cytokines, IL-1 $\beta$, IL- 6 and tumor necrosis factor- $\alpha$ (TNF- $\alpha$ ) in the BALFs, which were significantly elevated after SiNPs exposure (Fig. 2h-j). 
Oxidative stress is the most recognized mechanism mediating nanotoxicity, via acting on different intracellular organelles or activating many signaling pathways. As shown above, EPR analysis indicates that SiNPs have a strong ability to produce hydroxyl radicals. Thus, we further explored the role of oxidative stress in siNPs-induced pulmonary inflammation. PARP is one of the targets by oxidative stress and plays an important role in the DNA repair process. It was reported that PARP activation promotes inflammation by influencing the expression of proinflammatory mediators [22], and that administration of PJ34, a PARP inhibitor, markedly decreased lung inflammatory damage induced by bleomycin, an antitumor drug [16]. Consistently, SiNPs-induced adverse effects in the mice were strongly alleviated by treatment with PJ34 (Fig. 2a-i), with an exception that SiNPs-induced generation of TNF- $\alpha$ was not affected (Fig. 2j). Altogether, these in vivo experiments demonstrate that PARP is critically involved in SiNPsinduced generation of IL-1 $\beta$ and IL-6.

\section{Oxidative stress and PARP activation are involved in SiNPs-induced toxicity and inflammation in BEAS-2B epithelial cells}

After reaching the respiratory tract, SiNPs firstly contact with epithelial cells and cause damage before they are removed via phagocytosis by macrophages $[23,24]$. $\mathrm{Hu}$ man bronchial epithelial BEAS-2B cells and immortalized bone marrow-derived macrophages (iBMDMs) were used to further define the cellular and molecular mechanisms responsible for in vivo pulmonary inflammation and lung injury. Exposure to $12.5-200 \mu \mathrm{g} / \mathrm{mL}$ SiNPs for 24 and $48 \mathrm{~h}$ caused significant cell death in a dose- and time-dependent manner in BEAS-2B cells (Fig. 3a). Exposure to $100 \mu \mathrm{g} / \mathrm{mL}$ SiNPs for $24 \mathrm{~h}$ was used for further investigations. Under this condition, SiNPs increased the expression levels of IL- $1 \beta$ and IL-6 in BEAS-2B cells (Fig. 3b, c and Additional file 2: Figure S2). Notably, there was no detectable expression of TNF- $\alpha$, suggesting that SiNPs-induced generation of TNF- $\alpha$ in vivo in mice mainly by macrophages [25]. In addition, generation of CXCL-1 and CXCL-8, which target CXC chemokine receptors on neutrophils, was increased in BEAS-2B cells after SiNPs exposure (Fig. 3d, e and Additional file 2: Figure S2). Considering activation of PARP by oxidative stress, we evaluated SiNPs-induced production of ROS in BEAS-2B cells. Exposure to SiNPs enhanced ROS generation, which was significantly decreased by $\mathrm{N}$ acetyl-L-cysteine (NAC), a ROS scavenger (Fig. $3 \mathrm{f}$ and g). Correspondingly, SiNPs-induced reduction in the cell viability was largely rescued by NAC (Fig. 3h). In addition, SiNPs-induced production of cytokines and chemokines, as well as cell death, in BEAS-2B cells were significantly reduced by treatment with PJ34 (Fig. 3b-f and h), demonstrating critical involvement of PARP activation in SiNPs-induced inflammation and cytotoxicity in epithelial cells. Exposure of iBMDMs to $100 \mu \mathrm{g} / \mathrm{mL}$ SiNPs for $24 \mathrm{~h}$ induced generation of IL-6 and TNF- $\alpha$, which however was not sensitive to inhibition by treatment with PJ34 (Additional file 3: Figure S3). Taken together, these results suggest that lung epithelial cell inflammation plays a key role in mediating SiNPsinduced pulmonary inflammation and lung injury. Therefore, BEAS-2B cells were used in subsequent experiments to examine the PARP pathway in mediating SiNPs-induced damage to lung epithelial cells.

According to the FTIR spectrum, the surface of SiNPs is mainly composed of hydrogen-bonded silanols, which confer the potential to generate hydroxyl radicals (Fig. 1a-c). Thus, we studied the chemical basis of SiNPs-induced generation of ROS and cytotoxicity. Red blood cells (RBCs) are susceptible to oxidative damage, which leads to hemolysis, and the RBC lysis is regarded predictive of cytotoxicity [20, 21]. SiNPs caused dosedependent RBC lysis (Fig. 4a). Calcination at $600{ }^{\circ} \mathrm{C}$ to reduce the total hydroxyl content of silica surface by dehydroxylation significantly reduced hydrogen-bonded silanols on the SiNPs surface [20]. As expected, the ROS level was slightly but significantly decreased in BEAS-2B cells after exposure to calcined-SiNPs (Fig. $4 \mathrm{~b}$ and c) and hemolysis was also reduced in RBCs incubated with calcined-SiNPs (Fig. 4a). In addition, SiNPs-induced ROS production in BEAS-2B cells was attenuated by treatment with diphenyleneiodonium chloride (DPI), a NADPH oxidases inhibitor (Fig. 4d and e), suggesting that NADPH oxidases is also significantly involved in ROS generation, as reported in our previous study [19].

\section{SiNPs-induced PARP activation mediates alkalization and reduces the degradation capacity of lysosomes in BEAS- $2 \mathrm{~B}$ cells}

It is well documented that oxidative stress can induce lysosome damage [26]. A previous study reported that NPs imposed remarkable influence on lysosomes [27]. Lysosomal-associated membrane protein 1 (LAMP1) is considered as a lysosome marker and LAMP1 staining is routinely used to visualize lysosomal compartments [28]. Western blotting analysis showed modest but insignificant increase in the LAMP1 expression after SiNPs exposure (Fig. 5a). Fluorescence imaging using LysoTracker Green DND-26, a lysosome-specific probe revealed that the number of lysosomes was slightly increased and the size of lysosomes became significantly larger after uptake of SiNPs (Fig. 5b and c), likely due to defects in lysosome degradation [29]. Given the unique feature of lysosome for its highly acidic lumen $(\mathrm{pH} 4.5-$ 5.0) that provides optimal conditions for the catalytic 


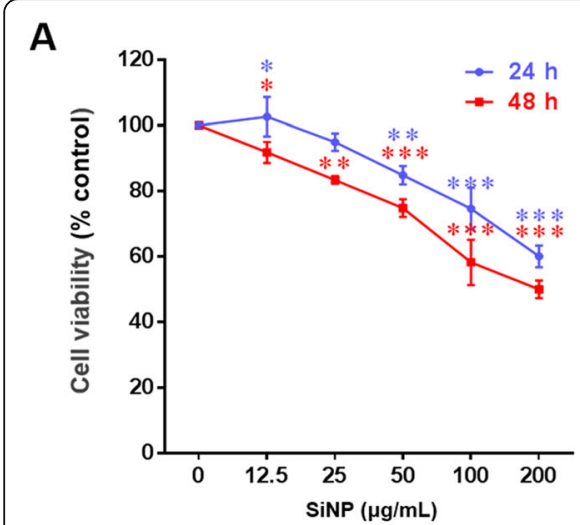

B

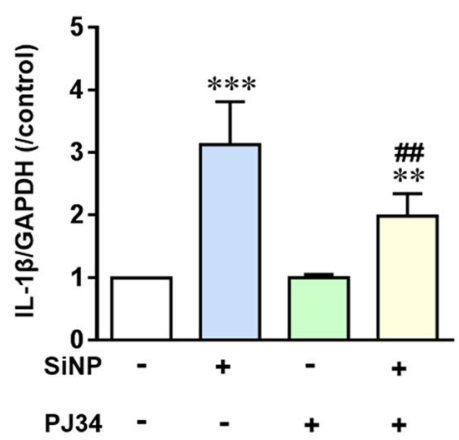

D

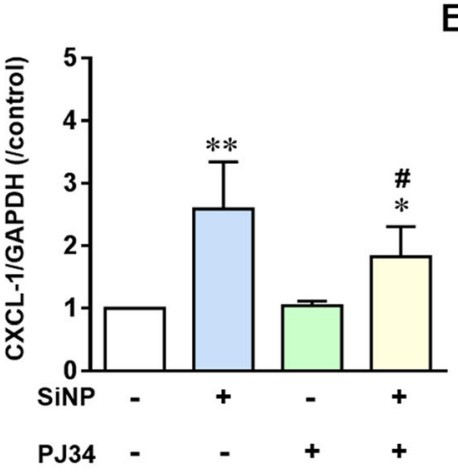

E

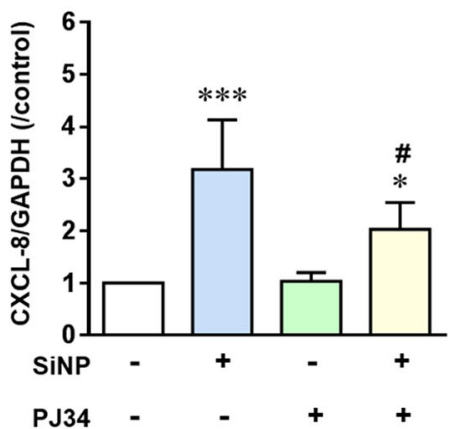

G

H

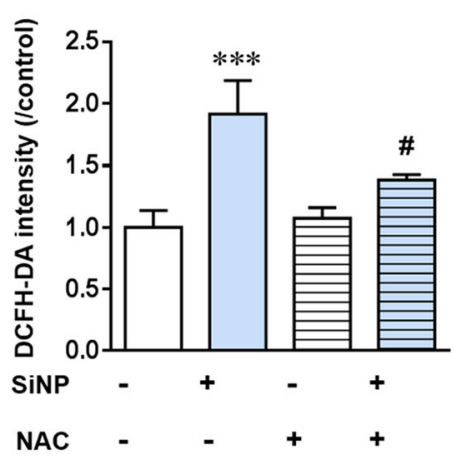

C

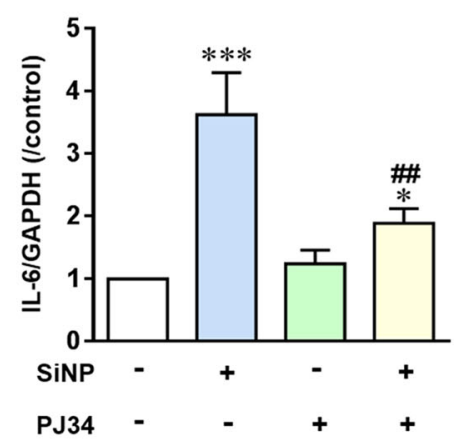

F

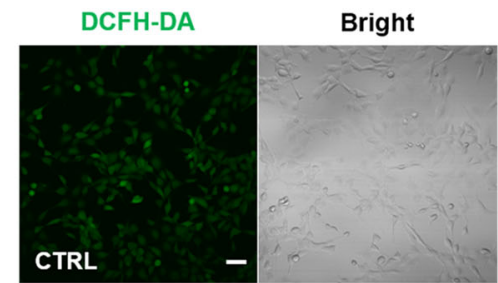

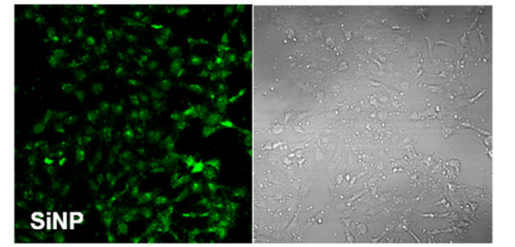
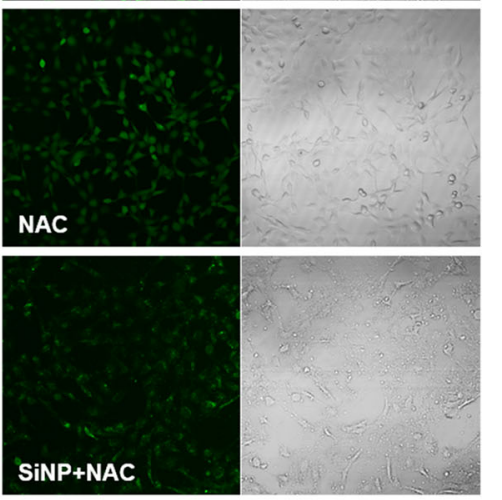

Fig. 3 Roles of oxidative stress and PARP activation in SiNPs-induced cytotoxicity in BEAS-2B cells. a Cell viability determined using a Cell Counting Kit-8 (CCK-8) after exposure to SiNPs at different doses (0, 12.5, 25, 50, 100 and $200 \mu \mathrm{g} / \mathrm{mL})$ for 24 and $48 \mathrm{~h}$. $\mathbf{b}$-e The levels of mRNA expression for IL-1 $\beta$ (b), IL-6 (c), CXCL-1 (d) and CXCL-8 (e) in cells under control or after exposure to SiNPs (100 $\mu \mathrm{g} / \mathrm{mL})$ in the absence or presence of PJ34 $(10 \mu \mathrm{M})$. $\mathbf{f}$ Representative confocal microscopic images showing DCFH-DA fluorescence intensity in cells under control condition (CTRL), or after treatment with SiNPs $(100 \mu \mathrm{g} / \mathrm{mL})$ for $12 \mathrm{~h}$ in the absence or presence of NAC $(5 \mathrm{mM})$, or NAC $(5 \mathrm{mM})$ alone. Scale bar $=50 \mu \mathrm{m}$. $\mathbf{g}$ Mean DCFH-DA fluorescence intensity under indicated conditions, as shown in $\mathbf{f}$, from 200 cells analyzed for each condition. $\mathbf{h}$ Cell viability under control condition and after exposure to SiNPs $(100 \mu \mathrm{g} / \mathrm{mL})$ for $24 \mathrm{~h}, \mathrm{NAC}(5 \mathrm{mM})$, PJ34 $(10 \mu \mathrm{M})$ or in combinations. ${ }^{*} P<0.05$, ${ }^{* *} P<0.01$, ${ }^{* * *} P<$ 0.001 compared to the control group. ${ }^{\#} P<0.05,{ }^{\# \#} P<0.01,{ }^{\# \# \# P}<0.001$ compared to SiNPs-treated group

function of hydrolytic enzymes, we expressed mAppleLAMP1-pHluorin in BEAS-2B cells to examine the luminal environments in the lysosomes. As a $\mathrm{pH}$-sensitive mutant of GFP, pHluorin is quenched in an acidic environment and emits red fluorescence in functional lysosomes while it produces yellow fluorescence in nonfunctional lysosomes [30]. As shown in Fig. 5d-f, like exposure to chloroquine (CQ), a lysosome inhibitor, used as a positive control, exposure to SiNPs resulted in significant accumulation of mApple-LAMP1-pHluorin 


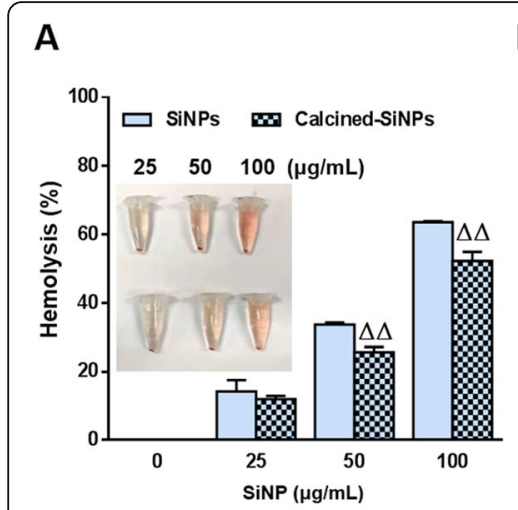

B

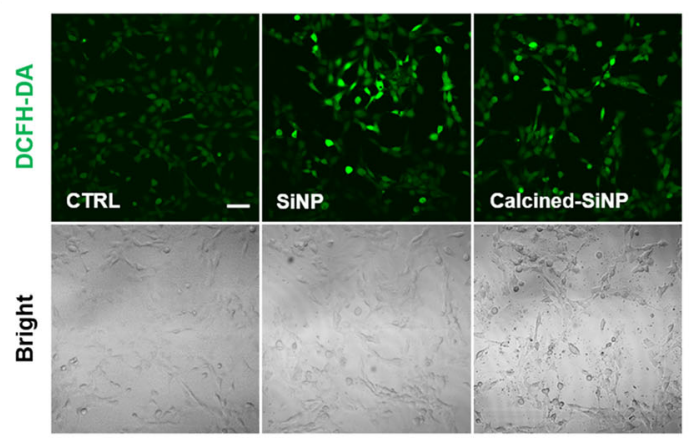

C

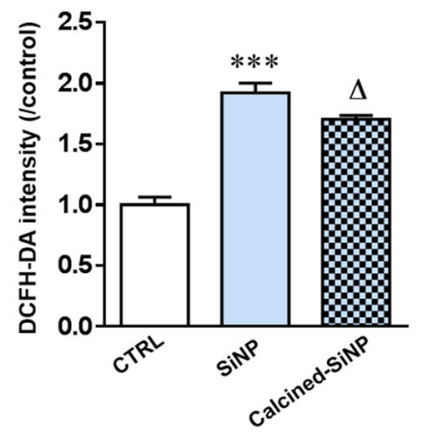

D

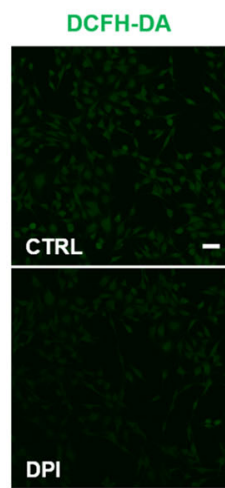

Bright

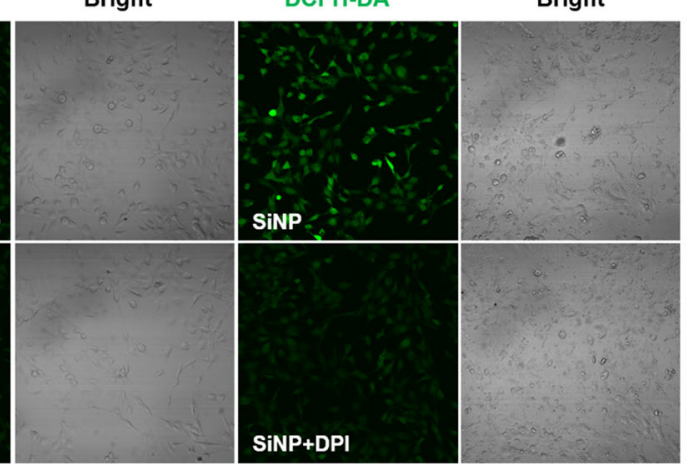

$\mathrm{E}$

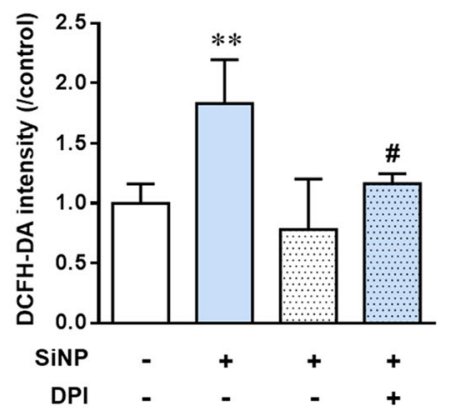

Fig. 4 Contribution of surface silanol groups and NADPH oxidases in SiNPs-induced oxidative stress. a Hemolysis to mouse RBCs after exposure to $25-100 \mu \mathrm{g} / \mathrm{mL}$ SiNPs $(100 \mu \mathrm{g} / \mathrm{mL}$ ) or calcined-SiNPs for $3 \mathrm{~h}$ at room temperature. The insert represents hemoglobin release indicated by red color in the supernatant. b Representative confocal microscopic images showing DCFH-DA fluorescence in BEAS-2B cells under control (CTRL) condition, or after treatment with SiNPs $(100 \mu \mathrm{g} / \mathrm{mL})$ or calcined-SiNPs $(100 \mu \mathrm{g} / \mathrm{mL})$. Scale bar $=50 \mu \mathrm{m}$. c Mean DCFH-DA fluorescence intensity under indicated conditions as shown in b, from 200 cells analyzed for each condition. $\mathbf{d}$ Representative confocal microscopic images showing DCFH-DA fluorescence in BEAS-2B cells under control (CTRL) condition or after treatment with SiNPs $(100 \mu \mathrm{g} / \mathrm{mL})$ in the absence or presence of DPI $(0.1 \mu \mathrm{M})$. e. Mean DCFH-DA fluorescence intensity under indicated conditions as shown in $\mathbf{d}$, from 200 cells analyzed for each condition. ${ }^{* *} P<0.01,{ }^{* * *} P<0.001$ compared to control group. ${ }^{\#} P<0.05$ compared to SiNPs-treated group. ${ }^{\Delta} P<0.05,{ }^{\Delta} P<0.01$ compared to calcined-SiNPs at the same concentration

related yellow puncta in BEAS-2B cells, confirming that SiNPs caused alkalinization that may reduce the degradation capacity of lysosomes.

To further investigate the effects of SiNPs on the degradation capacity of lysosomes in BEAS-2B cells, we performed DQ-BSA dequenching analysis. Under normal conditions, non-quenched proteins of DQ-BSA are released through the process of degradation by lysosomes, resulting in bright fluorescence [31]. As shown in Fig. 5g and $\mathrm{h}$, a decrease in DQ-BSA fluorescence was observed in cells after SiNPs exposure. Aspartic protease cathepsin D (CTSD) is one of the most abundant and functionally important lysosomal proteases, and its maturation and release to the cytosol can also reflect the degradation function of lysosomes [32]. Western blotting analysis showed the cytosolic level of mature CTSD was significantly decreased in SiNPs-exposed BEAS-2B cells (Fig. $5 \mathrm{i}$ and $\mathrm{j}$ ). Maturation of cathepsin proteases requires lysosomal acidification and thus alkalization can ultimately impair cathepsin-mediated protein degradation [33], which is in strong agreement with the lysosome impairment observed in our experiment. Finally, SiNPs-induced impairment in lysosome function was significantly mitigated by treatment with PJ34 (Fig. 4d-j), indicating a role of PARP in mediating SiNPs-induced detrimental effect.

\section{SiNPs-induced PARP-mediated lysosome impairment leads to blockage of autophagic flux}

Given the important function of lysosome in autophagy, lysosome impairment inevitably affects the autophagy flux. We therefore evaluated the progression of autophagy in BEAS-2B cells upon SiNPs exposure. Microtubule-associated light chain 3 II (LC3-II) is the most important marker of autophagy [29]. As shown in Fig. 6a, exposure to SiNPs for $24 \mathrm{~h}$ caused a significant 


\section{A}
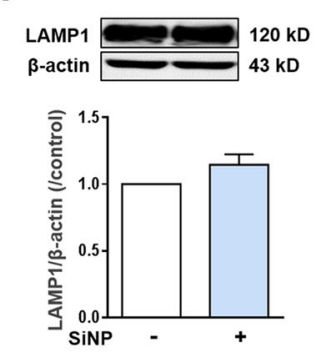

D

pHluorin-LAMP1 mApple-LAMP1 Merged
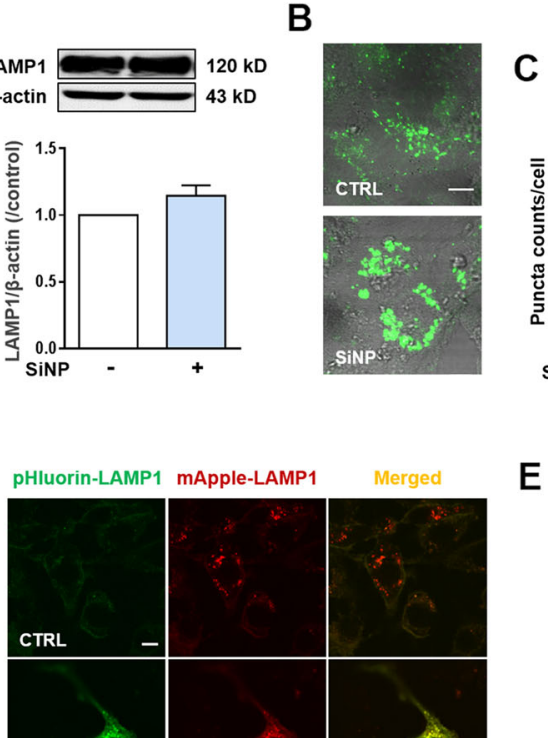

SiNP
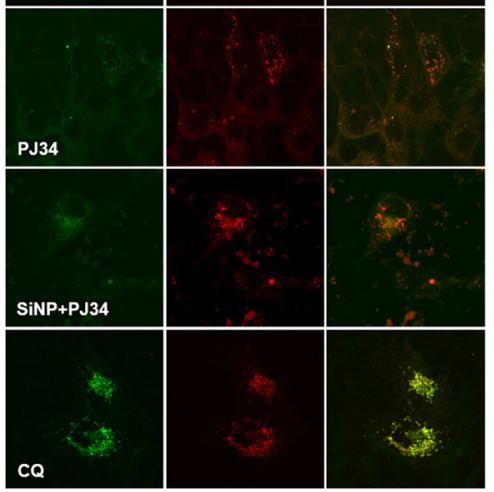

G

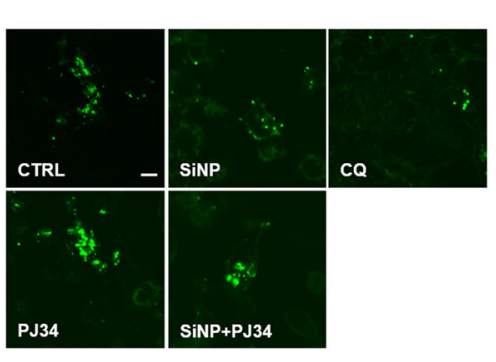

I

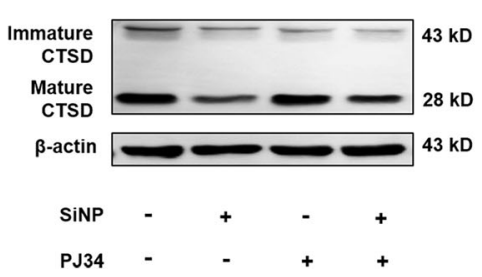

C
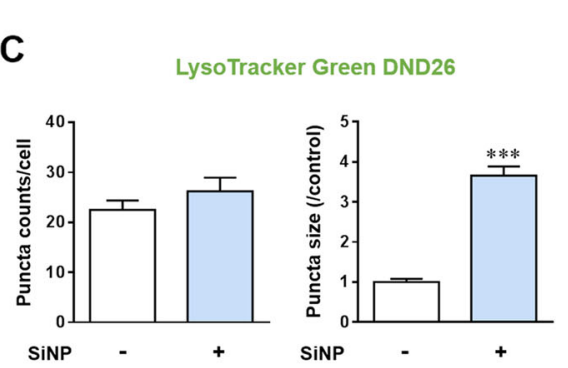

E
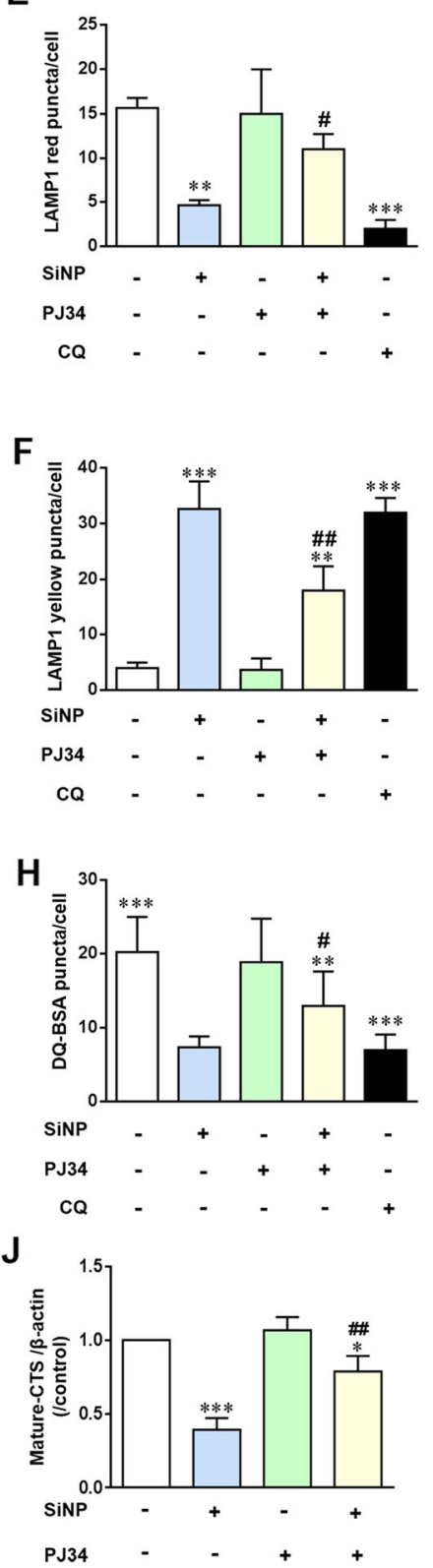

Fig. 5 (See legend on next page.) 


\section{(See figure on previous page.)}

Fig. 5 PARP activation mediates SiNPs-induced lysosomal alkalization and reduced degradation capacity in BEAS-2B cells. a LAMP1 expression determined by western blotting. b Representative images showing LysoTracker Green DND-26 fluorescence in cells under control conditions or after treated with SiNPs $(100 \mu \mathrm{g} / \mathrm{mL})$ for $24 \mathrm{~h}$. c The mean number and size of lysosomes in cells as shown in $\mathbf{b}$, from 50 cells for each condition. Scale bar $=10 \mu \mathrm{m}$. $\mathbf{d}$ Representative confocal microscopic images showing mApple-LAMP1-pHluorin in cells under control (CTRL) condition or after treatment with SiNPs $(100 \mu \mathrm{g} / \mathrm{mL})$ for $24 \mathrm{~h}$ in the absence or presence of PJ34 $(10 \mu \mathrm{M})$. Cells were incubated with CQ $(50 \mu \mathrm{M})$ for $3 \mathrm{~h}$ as the positive control. Scale bar $=10 \mu \mathrm{m}$. e-f Mean number of puncta in each cell under the conditions shown in $\mathbf{d}$, from 30 cells for each condition. $\mathbf{g}$ Representative confocal microscopic images showing DQ-BSA analysis of lysosomal proteolytic activity in cells under control condition or after treatment with SiNPs $(100 \mu \mathrm{g} / \mathrm{mL})$ for $24 \mathrm{~h}$ in the absence or presence of PJ34 $(10 \mu \mathrm{M})$. Scale bar $=10 \mu \mathrm{m}$. $\mathbf{h}$ Mean number of puncta in each cell under indicated conditions shown in $\mathbf{g}$, from 30 cells for each condition. i-j Western blotting analysis of CTSD in BEAS-2B cells under control condition or treatment with SiNPs $(100 \mu \mathrm{g} / \mathrm{mL})$ in the absence or presence of PJ34 $(10 \mu \mathrm{M})$, from three independent experiments. ${ }^{*} P<0.05$, ${ }^{* *} P<$ 0.01 , ${ }^{* *} P<0.001$ compared to the control cells, and ${ }^{\#} P<0.05$, ${ }^{\# \#} P<0.01$ compared to cells treated with SiNPs alone

and dose-dependent elevation in the LC3-II level, indicating an increase in the number of autophagosomes. Such an effect can be associated either with increased autophagosome formation, decreased autophagosomes degradation, or both [34]. To clarify whether the LC3-II accumulation resulted from autophagy activation and/or blockage of autophagic flux, we examined SQSTM1 in SiNPs-exposed BEAS-2B cells. SQSTM1 is a multifunctional protein that binds to LC3 and is degraded within the autolysosome [35], and thus enhanced SQSTM1 level has been regarded as an indicator for blockage of autophagic flux [36]. Our results showed an increase in the SQSTM1 level in BEAS-2B cells after SiNPs exposure (Fig. 6a), suggesting blockage of the autophagic flux. We analyzed transiently expressed GFP-RFP tandem fluorescent-tagged LC3 to further confirm the blockage of autophagic flux. The LC3-II positive autophagosomes are labeled with yellow puncta under normal condition, but are presented as red puncta after fusion with lysosomes to form autolysosomes [23, 32]. Exposure to SiNPs like CQ, significantly promoted accumulation of yellow puncta in BEAS-2B cells (Fig. 6b-d), indicating an increase in the number of autophagosomes. SiNPsinduced autophagy dysfunction was also alleviated by treatment with PJ34 (Fig. 6b-f). Taken together, our results indicate that SiNPs impair autophagic flux in a PARP-dependent manner in BEAS-2B cells.

It is known that induction of lysosomal membrane permeabilization (LMP) leads to inflammation by activating the NLRP3 inflammasome $[37,38]$. We were therefore interested in whether activation of the NLRP3 inflammasome contributed in SiNPs-induced inflammatory response [39]. SiNPs-induced increase in the IL-1 $\beta$ level was significantly inhibited by MCC950, a selective NLRP3 inhibitor (Additional file 4: Figure S4), indicating that activation of the NLRP3 inflammasome is involved in SiNPs-induced inflammation. Moreover, it is well known that autophagy plays an essential role in the inflammatory response of lungs to infection and stress [40]. A previous study reported that bismuth NPsinduced acute kidney injury was made worse on one hand by CQ, a blocker of autophagic flux, and on the other was attenuated by rapamycin, an autophagy inducer [41]. We showed that CQ significantly increased the generation of IL- $1 \beta$ and IL- 6 in BEAS-2B cells, whereas rapamycin resulted in an opposite effect (Additional file 5: Figure S5), supporting a causative relationship of autophagy with inflammatory response. Taken together, our results suggest that SiNPs-induced blockage of autophagic flux promotes inflammation.

\section{TRPM2 channel activation mediates SiNPs-induced inflammation via lysosome impairment and blockage of autophagic flux in BEAS-2B cells}

PARP is known to play a key role in mediating ROSinduced production of intracellular through the combined action of PARP and poly (ADP) glycohydrolase (PARG), the main endogenous agonist of TRPM2 channel $[42,43]$. We were prompted to further investigate involvement of the TRPM2 channel in mediating SiNPs-induced epithelial cell inflammation. We started with using compound A1, a TRPM2 channel selective inhibitor developed by our own lab [44]. Western blotting analysis demonstrates TRPM2 protein expression in BEAS-2B (Fig. 7a). Consistently, intracellular free $\mathrm{Ca}^{2+}$ concentration was assessed by using Fluo-3, a fluorescent $\mathrm{Ca}^{2+}$ indicator, showed that SiNPs-induced intracellular $\mathrm{Ca}^{2+}$ increase was inhibited by treatment with compound $\mathrm{A} 1$ as well as PJ34 (Fig. 7a). As shown above for PJ34, treatment with compound A1 also attenuated SiNPs-induced reduction in red puncta and increase in yellow puncta in lysosomes in BEAS-2B (Fig. 7b-d). In addition, compound A1 suppressed SiNPs-induced reduction in the level of mature CTSD (Fig. 7e). These results support critical involvement of the TRPM2 channel in SiNPs-induced lysosome impairment. As shown in Fig. 7f and g, compound A1 significantly alleviated SiNPs-induced accumulation of both LC3-II and SQSTM1, suggesting reversal of SiNPs-induced blockage of autophagic flux by inhibiting the TRPM2 channel. We next examined the effects of compound A1 on SiNPs-induced generation of pro-inflammatory cytokines and chemokines, and reduction in the cell 

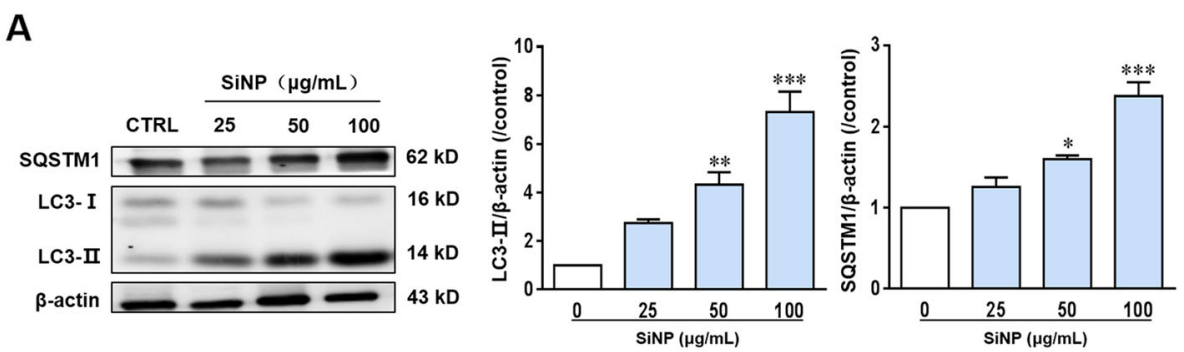

B

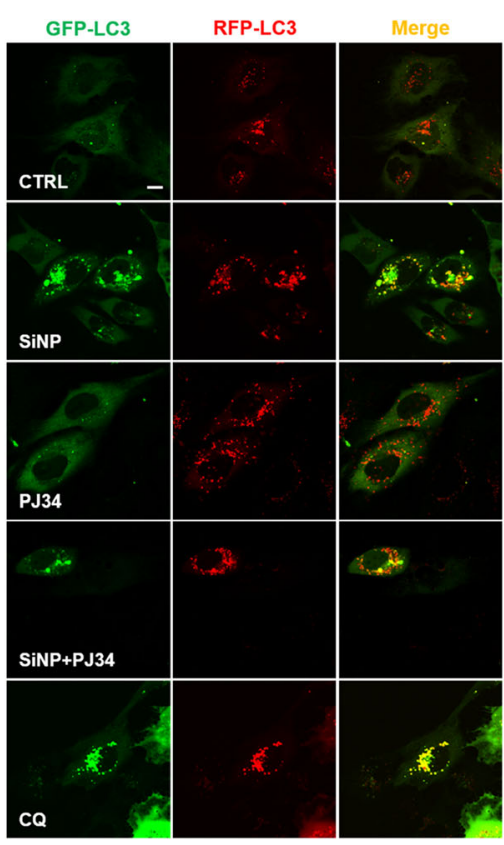

C

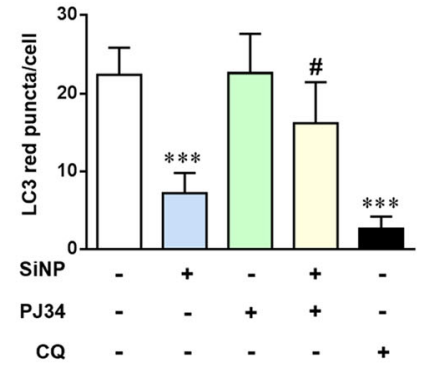

D

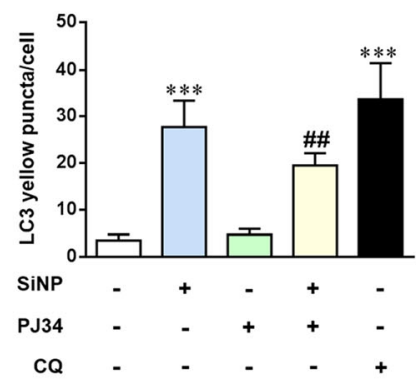

E

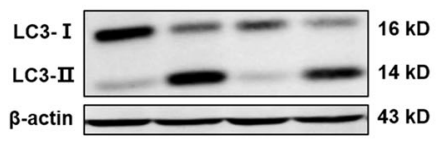

$\mathbf{F}$
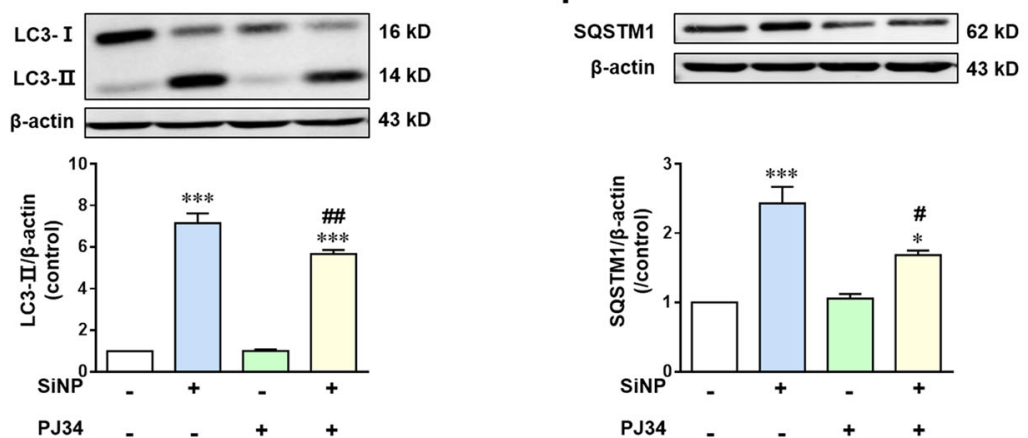

Fig. 6 PARP activation mediates SiNPs-induced blockage of autophagic flux in BEAS-2B. a Western blotting analysis of the levels of LC3 and SQSTM1 in BEAS-2B cells treated with different concentrations of SiNPs for $24 \mathrm{~h}$. $\mathbf{b}$ Representative confocal images showing GFP-LC3-RFP in cells treated with SiNPs $(100 \mu \mathrm{g} / \mathrm{mL})$ in the absence or presence of PJ34 $(10 \mu \mathrm{M})$ at $24 \mathrm{~h}$. Scale bar $=10 \mu \mathrm{m}$. c-d Mean number of yellow puncta (autophagosomes) and red puncta (autolysosomes) in each cell from 30 cells for each condition. e-f. Western blotting analysis of the levels of LC3 (e) and SQSTM1 (f) in BEAS-2B cells under control condition or after treated with SiNPs $(100 \mu \mathrm{g} / \mathrm{mL})$ in the absence or presence of PJ34 $(10 \mu \mathrm{M})$, from three independent experiments. ${ }^{*} P<0.05$, ${ }^{* *} P<0.01$, ${ }^{* * *} P<0.001$ compared to control cells, and ${ }^{\#} P<0.05$, ${ }^{\# \#} P<0.01$ compared to cells treated with SiNPs alone

viability in BEAS-2B cells. In SiNPs-exposed cells, both elevated generation of IL-1 $\beta$, IL-6, CXCL-1 and CXCL-8 (Fig. 8a-d and Additional file 2: Figure S2) and cell death (Fig. 8e) were also significantly prevented by treatment with compound A1. Collectively, these results indicate that PARP-dependent TRPM2 


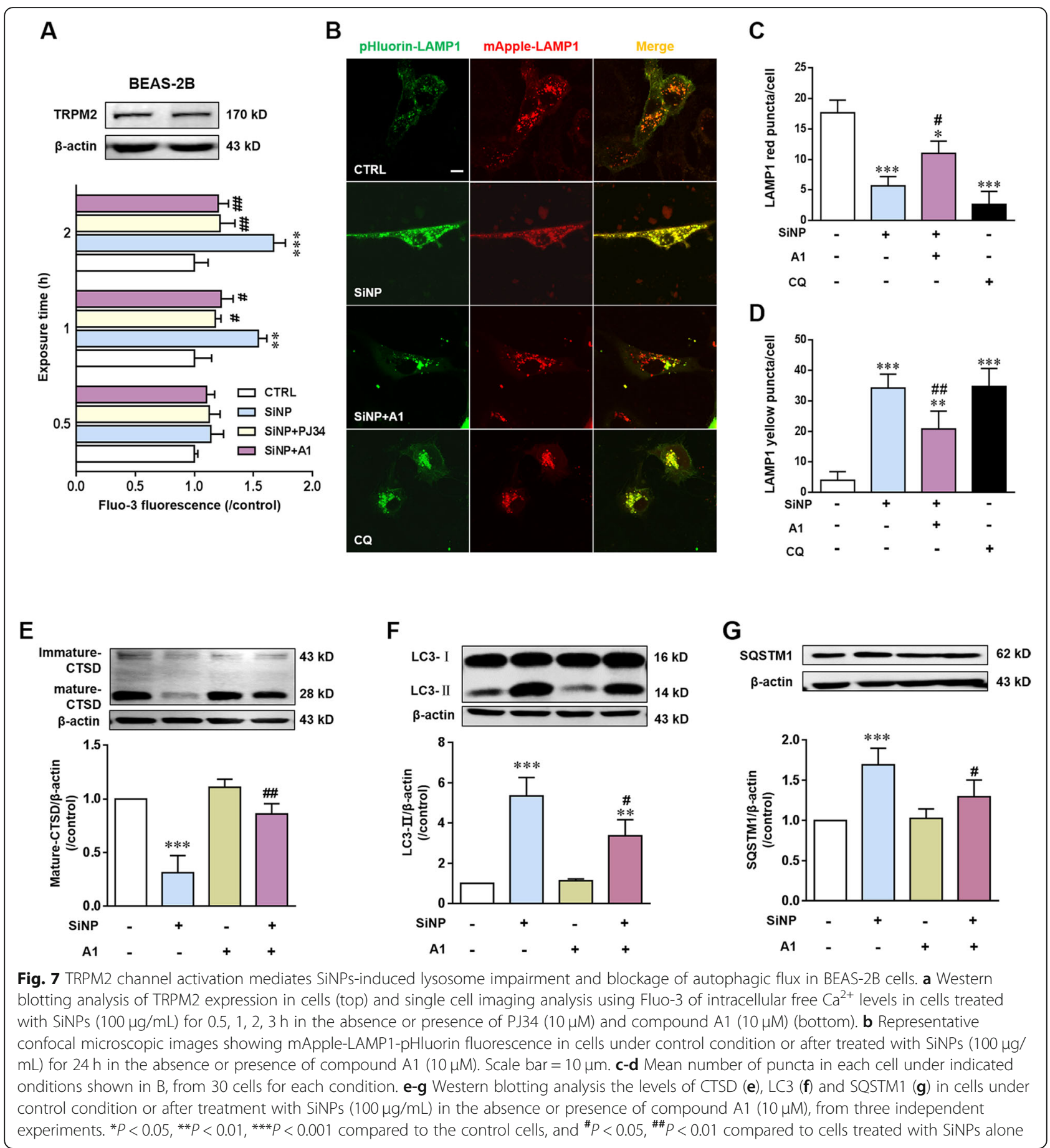

channel activation mediates SiNPs-induced inflammation via lysosome impairment and blockage of autophagic flux in BEAS-2B cells.

As a non-selective cation channel, TRPM2 plays a role in ROS-induced cell death through altering intracellular $\mathrm{Ca}^{2+}$ and/or $\mathrm{Zn}^{2+}$ homeostasis $[45,46]$. To define whether TRPM2-dependent alterations in intracellular $\mathrm{Ca}^{2+}$ and $\mathrm{Zn}^{2+}$ homeostasis in SiNPs-induced lysosome impairment and toxicity in BEAS-2B cells, we determined the effects of
BAPTA-AM and TPEN, chelators for $\mathrm{Ca}^{2+}$ and $\mathrm{Zn}^{2+}$ respectively, in combination with mApple-LAMP1-pHluorin assay and also acridine orange (AO) staining assay. $\mathrm{AO}$ emits green fluorescence in the cytosol and nucleus, but red fluorescence when it is accumulated in the acidic compartments [32]. It is anticipated for a decrease in granular red fluorescence with an increase in diffused green fluorescence is anticipated as a result of loss of acidic $\mathrm{pH}$ in the lysosomal lumen [47]. Treatment with compound A1 


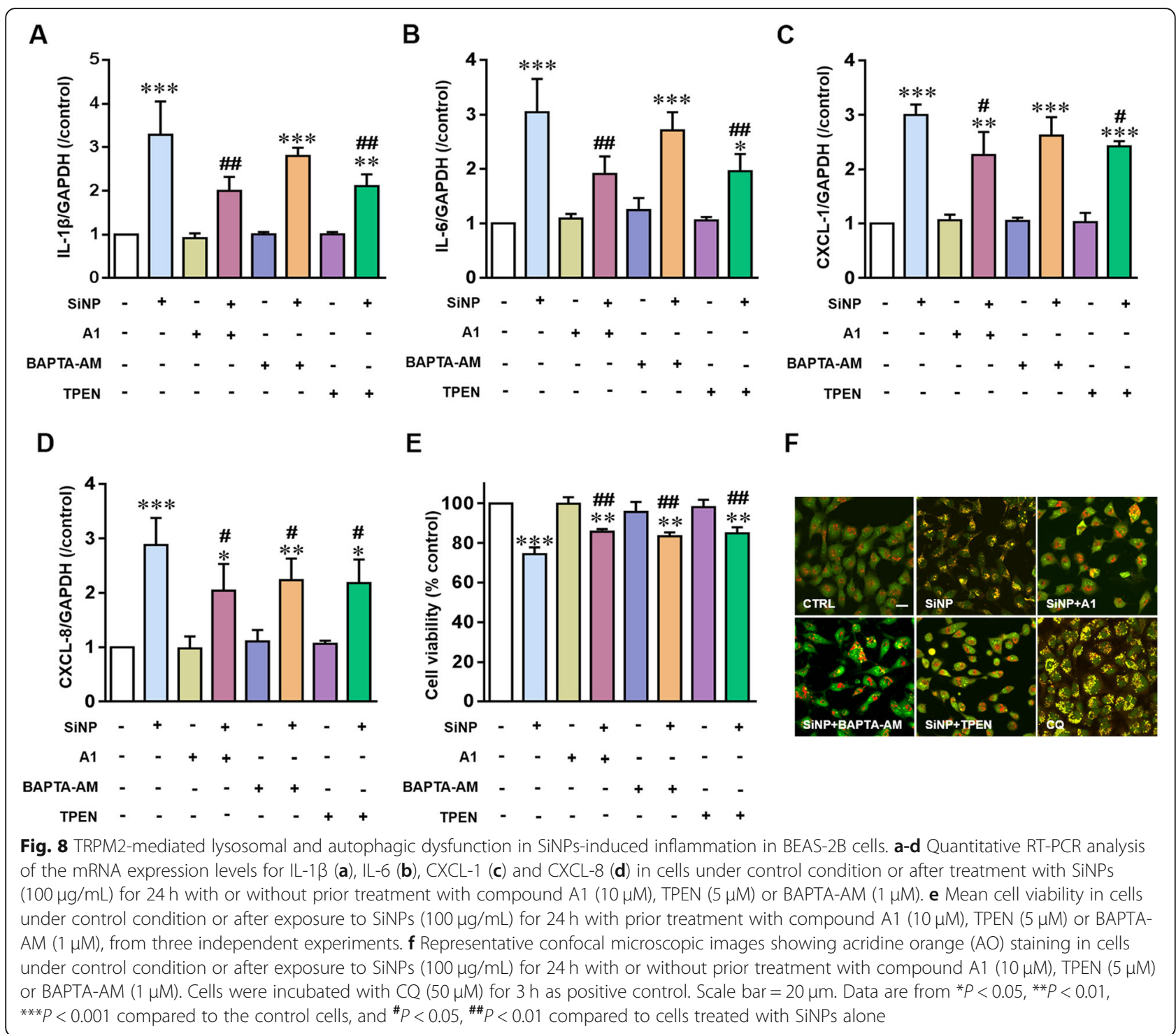

significantly increased red puncta and decreased green fluorescence in cells exposed to SiNPs or CQ, demonstrating the reversal of lysosomal alkalization by blocking the TRPM2 channel (Fig. 8f). Similarly, both BAPTA-AM and TPEN alleviated the SiNPs-induced lysosomal alkalization (Fig. 8f), suggesting that TRPM2-dependent alteration in the intracellular $\mathrm{Ca}^{2+}$ and $\mathrm{Zn}^{2+}$ homeostasis is critical in SiNPs-induced lysosome impairment. We further evaluated the effects of these two chelators on SiNPs-induced generation of cytokines and chemokines in BEAS-2B cells. As shown in Fig. 7a-d, TPEN significantly reduced SiNPsinduced generation of cytokines and cytokines, whereas BAPTA-AM had a modest but insignificant inhibition. Both chelators alleviated cell death induced by SiNPs (Fig. 8e). These results indicate a critical role for the TRPM2 channel, more specifically, TRPM2-mediated disruption in intracellular $\mathrm{Ca}^{2+}$ homeostasis, and particularly
$\mathrm{Zn}^{2+}$ homeostasis in SiNPs-induced lysosome impairment and inflammation in BEAS-2B cells.

\section{Genetic deletion of TRPM2 expression eliminates SiNPs- induced pulmonary inflammation and lung injury in C57BL/6 mice}

To further verify the significance of our in vitro findings, we examined SiNPs-induced lung injury and pulmonary inflammation in the Trpm $2^{-/-}$C57BL/6 mice. In contrast with the WT mice, the Trpm $2^{-/-}$mice showed no significant lung tissue edema and infiltration of inflammatory cells after SiNPs exposure (Fig. 9a). SiNPs also induced no increase in total proteins and LDH release in the Trpm $2^{-/-}$mice (Fig. 9b and c). Most importantly, SiNPsinduced increase in generation of IL- $1 \beta$ and IL- 6 was completely absent in the Trpm $2^{-/-}$mice (Fig. 9d and e). However, the Trpm $2^{-1-}$ mice after SiNPs exposure still 


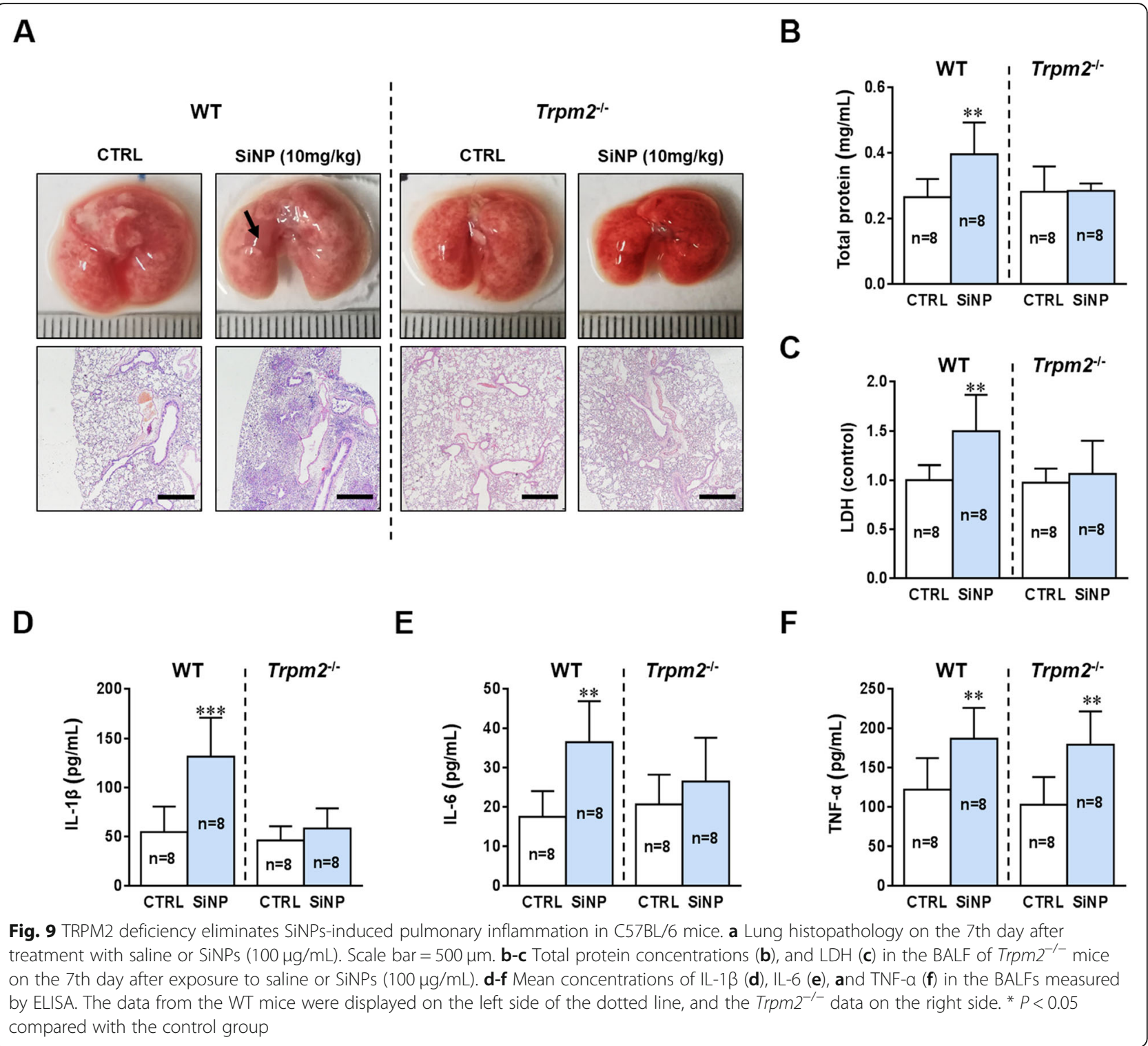

exhibited generation of TNF- $\alpha$ at a similar level to the WT mice (Fig. 9f), which was in line with no effect of treatment with PJ34 on TNF- $\alpha$ generation under in vivo (Fig. 2j) and in vitro conditions (Additional file 3: Figure S3). Exposure to SiNPs increased the numbers of total cells, macrophages, neutrophils and lymphocytes in the Trpm $^{-1-}$ mice, but SiNPs-induced increases in the $\operatorname{Trpm} 2^{-1-}$ mice were significantly smaller than those in the WT mice after exposure to SiNPs (Additional file 6: Figure S6). Taken together, the results indicate that the TRPM2 channel plays a key role in SiNPs-induced lung injury and pulmonary inflammation.

\section{Discussion}

With SiNPs widely used in food, medicine, agriculture and consumer products, concerns grow regarding their potential risks to human health and the environment. Toxicology of silica materials via inhalation has been reported extensively. While amorphous silica is generally considered safe by the U.S. Federal Drug Administration [48], there is accumulating evidence suggesting the toxicity of amorphous silica nanoparticles [49-51], since Song et al firstly reported that lung toxicity might be induced by long-term exposure to nanoparticles in 2009 [52]. Thus, effective protective methods appear to be important in terms of protecting workers from illness caused by exposure to nanoparticles. Fumed silica as the widely-used commercial SiNPs is one of the two principal classes of amorphous silica nanoparticles. In our study, we first confirmed the toxicological effects of SiNPs on lungs in vivo in mice. The dose range of 2.7 to $15.53 \mathrm{mg} / \mathrm{kg}$ SiNPs exposed to mice used in our study is 
thought close to that exposed to human population [53]. As has been well documented, immune response is a complex process, composed of recruitment of many types of immune cells and subsequent generation of pro-inflammatory cytokines and chemokines at different time courses. A previous study showed that upregulation of cytokines occurred at an early stage after i.t. instillation with SiNPs and lasted for 1 week, while increases in total cells and proteins in the BALFs were only observed 1 week after exposure [54]. In order to take various factors into account, we examined the mice on the 7th day following i.t. instillation of $10 \mathrm{mg} / \mathrm{kg}$ SiNPs. Under such conditions, SiNPs induced severe pulmonary inflammation in WT C57BL/6 mice. Of note, while i.t. instillation has been commonly used experimentally to introduce NPs exposure, it may produce different effects on the lungs, hearts and other organs compared with actual exposure to human population, due to delivery of single high-dose to lungs rather than long-term and repeated exposure to low doses, which should be considered in future studies.

We studied the chemical basis for the ability of SiNPs to induce ROS generation. It has been postulated that the toxicity of amorphous silica is related to the number of silanol groups on the surface $[1,4,20]$. As was reported, fumed SiNPs undergo a progressive surface dihydroxylation leading to a reduction in the total and hydrogen-bonded silanol concentrations over the temperature range from $200^{\circ} \mathrm{C}$ to $800^{\circ} \mathrm{C}$ [20]. Consistently, calcination of SiNPs to $600{ }^{\circ} \mathrm{C}$ significantly reduced the total hydroxyl content and hydrogen-bonded silanols on the surface. This was further confirmed by the reduced ability of calcinated SiNPs to induce ROS production in BEAS-2B cells and hemolysis to RBCs (Fig. 4a-c). Since the surface silanol groups play a more important role in oxidative stress induced by SiNPs, modifications should be considered during synthesis in order to reduce the toxicity of SiNPs. Such a notion is consistent with a recent study showing that the surface silanol content in fumed silica has a key role in, but is not the sole factor, determining the cytotoxicity [55] and providing a starting point for the synthesis of nano-silica materials with less or no toxicity.

We investigated, using BEAS-2B cells, the molecular mechanism underlying SiNPs-induced inflammation in human bronchial epithelial cells, which acts as the first physical barrier to defense against exogenous stimuli. Autophagy dysfunction has been considered to be a potential toxic effect of nanoparticles that results in cytotoxicity and inflammation [56]. Here, our studies showed that SiNPs exposure activated the TRPM2 channel through ROS/PARP pathway, which induced lysosome impairment and subsequent blockage of autophagic flux in epithelial cells. So far, most studies focus on the effects of nanoparticles on autophagy induction rather than the process of autophagy degradation [4]. Yu et al. showed that SiNPs increased formation of autophagosomes and autolysosomes in HepG2 cells [57]. Duan et al. reported that SiNPs induced autophagic activity in endothelial cells, accompanied by disturbing $\mathrm{NO} / \mathrm{NOS}$ activity and inducing inflammatory response, via inhibiting the PI3K/Akt/ mTOR signaling pathway [58]. In recent years, attention has been drawn to the effects of SiNPs on autophagic flux. Wang et al. reported that SiNPs induced autophagosome accumulation in hepatocytes via activating the EIF2AK3 and ATF6 UPR pathways without effect on lysosomal function [59], whereas Schütz et al. showed accumulation of SiNPs in HeLa cells caused defective autophagic flux and lysosomal dysfunction, albeit without effect on lysosomal acidification or intralysosomal hydrolase activity [9]. A separate study showed that exposure to zinc oxide-NPs impaired autophagic flux and acute lung injury, but it did not investigate the effects on lysosome function [60]. Two in vitro studies reported that gold NPs [29] and carbon nanotubes [61] induced lysosome impairment and subsequent blockage of autophagic flux, but the associations with cytotoxicity and inflammatory responses were not established. Therefore, our finding provide new insights into the underlying mechanisms by showing ROS production, lysosome impairment and autophagy dysfunction and their close interplays in SiNPs-induced inflammatory responses and toxicity to lungs. Such novel findings are helpful to better understand the cytotoxicity and pulmonary fibrosis as a result of exposure to other nanomaterials.

More significantly, our study shows the TRPM2 channel as a key mechanism for SiNPs-induced pulmonary inflammation and lung injury. TRPM2 channel is expressed in various types of immune cells such as dendritic cells [62, 63] and neutrophils [64, 65], and epithelial cells $[16,66,67]$ as well as macrophages and is important in inflammation $[16,68,69]$. Our in vivo evidence indicates that TRPM2 channel is critically involved in SiNPs-induced lung injury and increase in the number of mcarophages, neutrophils and lymphocytes. Moreover, SiNPs-induced release of IL-1 $\beta$ and IL- 6 also strongly depends on TRPM2 channel, suggesting critical involvement of the TRPM2 channel in SiNPs-induced inflammation. It is well known that epithelial cells, macrophages and neutrophils can mediate generation of cytokines. Our in vitro evidence supports TRPM2 channel is required for SiNPs-induced generation of cytokines in BEAS-2B rather than in iBMDMs. Interestingly, TRPM2 plays a critical role in SiNPs-induced generation of CXCL-1 and CXCL-8 in BEAS-2B cells. CXCL-1 and CXCL-8 play a key role in neutrophil infiltration and subsequent induction of macrophages to a pro- 
inflammatory phenotype and robust IL-1 $\beta$ release [70]. Our results suggest that TRPM2 channel in epithelial cell is critical for SiNPs-induced neutrophil infiltration and macrophage migration, which might contribute to the SiNPs-induced generation of IL- $1 \beta$, IL- 6 and TNF- $\alpha$. However, our results suggest that TRPM2 in macrophages may be not critically involved in SiNPs-induced inflammation. Previous studies had reported that TRPM2 played a key role in inflammation. For example, TRPM2 deficiency suppressed exacerbation of inflammation in mouse model of colitis [68]. In contrast, there is evidence to suggest that IL- 6 release was increased in TRPM2-deficient mice in sepsis model [71]. Herein, the role of TRPM2 channel in inflammation seems to depend on specific physiological and pathological conditions.

Our study further shows that the TRPM2 channel mediates SiNPs-induced lysosome impairment and inflammation by disrupting the intracellular $\mathrm{Ca}^{2+}$, particularly $\mathrm{Zn}^{2+}$ homeostasis. A previous study reported that exposure of pancreatic $\beta$-cells to high glucose induced oxidative stress and subsequent TRPM2 channel-mediated $\mathrm{Ca}^{2+}$ influx to cause lysosomal permeabilization and redistribution of lysosomal $\mathrm{Zn}^{2+}$ to mitochondria [72]. Li et al [73] have proposed a positive feedback mechanism for ROS-induced neuronal death, by which TRPM2 channel activation triggers lysosomal dysfunction, lysosomal $\mathrm{Zn}^{2+}$ release, mitochondrial $\mathrm{Zn}^{2+}$ accumulation, mitochondrial dysfunction and ROS generation. Such effects were suppressed by treatment with PJ34, TRPM2 inhibitors or TPEN. A similar mechanism may operate in mediating SiNPs-induced lysosome impairment in BEAS-2B cells. However, these effects resulting from exposure to SiNPs were not strongly attenuated but not fully abolished by inhibiting PARP or TRPM2 channel, suggesting involvement of other mechanisms, which needs further study. In addition, it is interesting to note that TRPM2 knockout completely eliminated SiNPs-induced generation of IL-1 $\beta$ and IL-6, differing from in vitro experiments where inhibition of the TRPM2 channel with compound A1 only partially alleviated SiNPs-induced generation of cytokines. Such a difference likely reflects the extent of TRPM2 channel inhibition by pharmacological and genetic means. Compound $\mathrm{A} 1$ at high concentrations was cytotoxic, hindering us from testing anti-inflammatory effects of compound $\mathrm{A} 1$ at increased concentrations. In addition, TRPM2 knockout blocked not only the function of TRPM2 channel in the ROS/PARP/ TRPM2 signaling, but also other possible inflammatory effects mediated by the TRPM 2 channel. Taken together, this study shows the importance of the ROS/PARP/TRPM2 signaling pathway in SiNPs- induced pulmonary inflammation. Targeting the TRPM2 channel may provide an intervention strategy to mitigate the toxic effects of exposure to nanomaterials.

\section{Conclusions}

In summary, for the first time, we show that the ROS/ PARP/TRPM2 signaling is critical in SiNPs-induced pulmonary inflammation, and that the surface silanol groups of SiNPs, especially the hydrogen-bonded silanols, play an important role in the generation of hydroxyl radicals. SiNPs exposure induces lysosome impairment and subsequent blockage of autophagic flux, via ROS generation, TRPM2 channel activation and TRPM2-mediated alteration in intracellular $\mathrm{Zn}^{2+}$ and $\mathrm{Ca}^{2+}$ homeostasis. As a result, dysfunctional autophagy triggers generation of pro-inflammatory mediators leading to pulmonary inflammation. A brief conceptual diagram is presented in Fig. 10. These findings may offer a new strategy to alleviate nanomaterials-induced toxicity by blocking the TRPM2 channel.

\section{Methods \\ Characterization of silica nanoparticle (SiNPs)}

Silicon dioxide nanoparticles used in this study were obtained from Sigma-Aldrich ((particle size: $10-20 \mathrm{~nm}$, 99.5\% purity) St Louis, MO, USA) and was dispersed in distilled water as stock, and sonicated before use (160 W, $20 \mathrm{kHz}, 5 \mathrm{~min}$; JY 92-IIN; Scientz, Ningbo, China). The morphology of SiNPs was examined by transmission electron microscopy (Tecnai G2 Spirit $120 \mathrm{Kv}$, FEI, Czech). The hydrodynamic diameter and zeta potential of SiNPs in distilled water and RPMI-1640 culture media with $10 \%$ fetal bovine serum (FBS) were measured using dynamic light scattering (Nano-S90, Malvern Instruments, UK) and Zetasizer Nano Series (Malvern Instruments, UK), respectively. To confirm the endotoxin content of SiNPs, Bioendo EC Endotoxin Test Kit (EC325454S, Bioendo, Xiamen, China) was used and $0.0748 \pm 0.0111 \mathrm{EU} / \mathrm{mL}$ was detected in SiNPs at $100 \mu \mathrm{g} /$ $\mathrm{mL}$.

The surface area of SiNPs was measured by the BET method from $\mathrm{N}_{2}$ sorption isotherm, which was recorded by a 24 -h vacuum outgassing process at $120^{\circ} \mathrm{C}$ on automatic specific surface and aperture analysis instrument (AUTOSORB-IQ2-MP). The weight changes in dehydration and dihydroxylation of SiNPs were determined on a Q50 thermogravimeter (TA instruments, USA), in which $3 \mathrm{mg}$ of SiNPs was gradually heated to $800{ }^{\circ} \mathrm{C}$ in air with a heating rate of $10^{\circ} \mathrm{C} / \mathrm{min}$. Fourier transform infrared (FTIR) spectrum was recorded on a Bruker Vector 22 spectrometer with $\mathrm{KBr}$ pellet. The ability of SiNPs to generate free radicals was examined using a Bruker A300 electron paramagnetic (EPR) instrument. The X- 


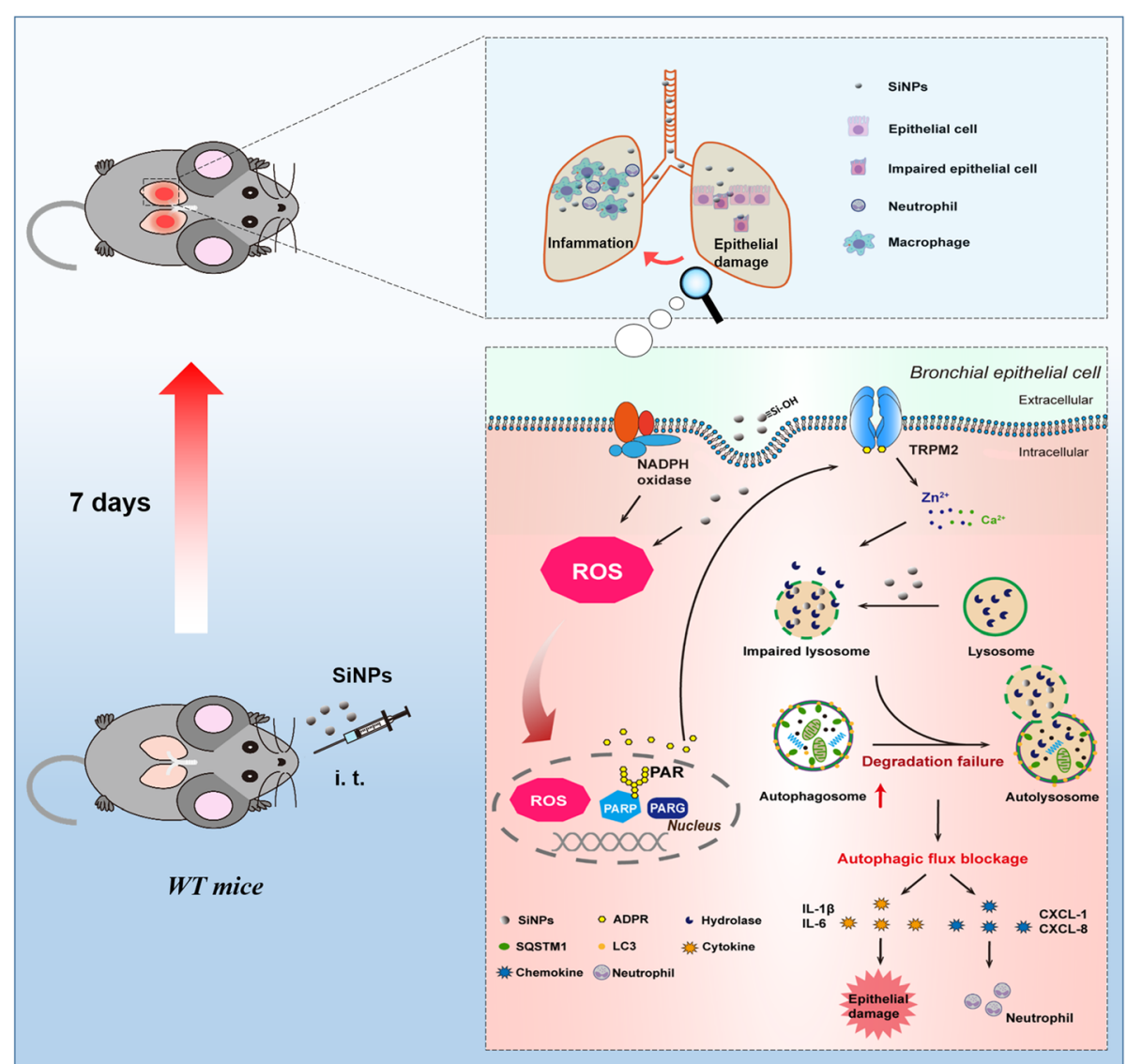

Fig. 10 Schematic illustration of the ROS/PARP/TRPM2 signaling pathway that mediates SiNPs-induced pulmonary inflammation in mice. SiNPS are ingested through intratracheal exposure and, upon endocytosis into bronchial epithelial cells, induce ROS production, which activates the TRPM2 channel through the PARP-mediated generation of ADPR in the nucleus. TRPM2 channel activation in turn increases intracellular zinc and calcium ions to impair the degradation function of lysosomes. Lysosomal dysfunction blocks autophagic flux that triggers inflammation by generating cytokines, IL-1 $\beta$ and IL-6, and also chemokines, CXCL-1 and CXCL-8, which are critical for neutrophil recruitment

band $(9.8 \mathrm{GHz})$ spectrum was recorded at room temperature using 5,5-dimethyl-pirroline- $N$-oxide (DMPO) as the spin-trapping molecule. SiNPs $(5 \%$ in w: v) were dispersed in the mixture of equal volume of DMPO aqueous solution $(12.5 \mathrm{mg} / \mathrm{mL})$ and $\mathrm{H}_{2} \mathrm{O}_{2}(30 \%)$.

\section{Hemolysis assay}

Mouse blood samples were obtained from three healthy mice and stabilized with EDTA. After the serum was removed by centrifugation and suction, red blood cells (RBCs) were washed several times with sterile isotonic PBS until the supernatant was transparent. Following the last wash, RBCs were diluted to $1 / 10$ of the original volume with sterile isotonic PBS. $300 \mu \mathrm{L}$ of RBC suspension was mixed with $1200 \mu \mathrm{L}$ of isotonic PBS as a negative control, $1200 \mu \mathrm{L}$ of nanopure water as a positive control, or $1200 \mu \mathrm{L}$ of SiNPs or calcined-SiNPs at $600{ }^{\circ} \mathrm{C}$ with concentrations from 25 to $100 \mu \mathrm{g} / \mathrm{mL}$. The mixtures were vortexed and left to rest for $3 \mathrm{~h}$ at room temperature. The samples were centrifuged at $10000 \times g$ at $4{ }^{\circ} \mathrm{C}$ for $3 \mathrm{~min}$ and the absorbance of the supernatants at $541 \mathrm{~nm}$ was measured using a microplate reader (Tecan Infinite M200, Switzerland). Hemolysis was calculated by the difference in the absorption between SiNPs-treatment sample and negative control, as percentage of the difference in the absorption between positive and negative controls.

\section{Animals and exposure}

Eight-week-old C57BL/6 WT and Trpm $2^{-1-}$ male mice were used in this study. The WT mice were purchased from Shanghai SLAC Laboratory Animal Co. Ltd. (Shanghai, China), and the Trpm $2^{-/-}$mice were bred in Zhejiang University after introduced from University of Leeds, where the transgenic mice were generated. Mouse embryonic clones carrying the mutated allele lacking exons 17 and 18 of the trpm2 gene and a neomycin resistance and thymidine kinase selection cassette were injected into C57BL/6-derived blastocysts. Homozygous Trpm $2^{-/-}$mice were 
obtained by several rounds of cross-breeding and validated by PCR of genomic DNA [74]. All mice in this study were group-housed in cages with regular rodent chow and mineral water provided ad libitum under standard breeding conditions with a 12-h reversed light/dark cycle and $\sim 22^{\circ} \mathrm{C}$. All animal experiments were performed strictly in accordance with the ethical guidelines by the Ethics Committee of Laboratory Animal Care and Welfare, Zhejiang University School of Medicine. The WT mice were randomized into four groups ( $n=8$ for each group): control group, SiNPs-treatment group, PJ34-treatment group, and SiNPs/PJ34-treatment group. The Trpm $2^{-/-}$mice were divided into two groups ( $\mathrm{n}=8$ for each group): control group and SiNPs-treatment group. All mice in the SiNPs-treatment groups were anesthetized using isoflurane and SiNPs suspended in normal saline (6 $\mathrm{mg} / \mathrm{mL}$ ) were intratracheally instilled slowly with a dosage of $10 \mathrm{mg} / \mathrm{kg}$ body weight $(40 \mu \mathrm{L})$. PJ34 (HY13688A, MCE, USA) was dissolved in normal saline and administered to mice intraperitoneally $1 \mathrm{~h}$ with a dosage of $10 \mathrm{mg} / \mathrm{kg}$ body weight before i.t. instillation with SiNPs and were daily injected for another 7 days without SiNPs exposure. The control groups received normal saline.

\section{Bronchoalveolar lavage fluids (BALFs) and cell counts}

All mice were sacrificed on the 7th day after exposure to SiNPs. The trachea was clearly visualized after separating the tissues and skin, and a 20-gauge cannula was inserted into the trachea. The lungs were lavaged with $0.8 \mathrm{~mL}$ of ice-cold PBS for twice and $1.2 \mathrm{~mL}$ of BALFs collected from each mouse. Then BALFs were centrifuged at 500x $g$ at $4{ }^{\circ} \mathrm{C}$ for $15 \mathrm{~min}$. The supernatant was transferred to a new tube and frozen for subsequent analysis. The cell pellet was suspended in $500 \mu \mathrm{L}$ of PBS and the total cell counts were counted using hemocytometer. Counting different cells (macrophages, neutrophils and lymphocytes) was evaluated on a cytospin slide stained with Wright-Giemsa dyes (BA-4017, Baso, Zhuhai, China) and 300 cells per mouse were examined under a light microscope.

\section{Analysis of BALFs}

The concentration of total proteins in the BALFs was measured using Enhanced BCA Protein Assay Kit (P0009, Beyotime, Shanghai, China). The levels of IL-1 $\beta$, IL-6, TNF- $\alpha$ in the BALFs were determined using ELISA Kit (ELM-IL1 $\beta$-1/ELM-IL-6-1/ELM-TNF $\alpha-1, \quad$ Raybiotech, GA, USA), and the amount of LDH released in the BALFs was assessed using a LDH Cytotoxicity Assay Kit (C0017, Beyotime, Shanghai, China), according to the manufacturers' instructions.

\section{Histological examination}

Mice were euthanized under ether anesthesia on the 7th day after SiNPs exposure. All mice were placed on an iced table. The right lung was stored in liquid nitrogen, and the left lung was fixed in $4 \%$ paraformaldehyde for $48 \mathrm{~h}$ at $4{ }^{\circ} \mathrm{C}$, embedded in paraffin, and serially cut into $5-\mu \mathrm{m}$ sections. After dewaxing, the sections selected from each mouse were stained with hematoxylin and eosin (H\&E) and evaluated the histology of the lung tissues under a light microscope (Olympus BX53, Tokyo, Japan).

\section{Cell culture}

The non-tumorigenic human bronchial epithelial cells (Ad12-SV40 immortalized) BEAS-2B were kindly provided by Prof. Xiangwei Gao (Institute of Environmental Medicine, Zhejiang University School of Medicine, China) and cultured in Roswell Park Memorial Institute medium (RPMI-1640, 31,800, Gibco, USA) with $10 \% \mathrm{FBS}, 100 \mathrm{IU} / \mathrm{mL}$ penicillin and $100 \mu \mathrm{g} /$ $\mathrm{mL}$ streptomycin in a $5 \% \mathrm{CO}_{2}$ humidified atmosphere at $37^{\circ} \mathrm{C}$. Cells were seeded at a density of $5 \times 10^{3}$, $1.5 \times 10^{4}, 3 \times 10^{5}$ cells/well in 96-well, 24-well and 6well plates, respectively, to conduct subsequent different experiments. Treatment with SiNPs was performed as described previously. Briefly, BEAS-2B cells were seeded overnight at a $60-70 \%$ confluence and treated with SiNPs or with an equal volume of PBS. The immortalized bone marrow derived macrophages (iBMDMs) derived from C57BL/6 mice were kindly provided by Prof. Feng Shao (National Institute of Biological Sciences, China) [75, 76]. iBMDM cells were cultured in Dulbecco's Modified Eagle Medium (DMEM, 12800, Gibco, USA) with 10\% FBS, $100 \mathrm{IU} /$ $\mathrm{mL}$ penicillin and $100 \mu \mathrm{g} / \mathrm{mL}$ streptomycin in a $5 \%$ $\mathrm{CO}_{2}$ humidified atmosphere at $37^{\circ} \mathrm{C}$. Both of two types of cells were exposed to SiNPs following pretreatment with various inhibitors and chelators for 30 min.

\section{Cell viability assay}

The viability of BEAS-2B cells was determined using Cell Counting Kit-8 (C0043, Beyotime, Shanghai, China) according to the manufacturer's instructions. Briefly, cells were seeded in 96-well plates at a density of $5 \times 10^{3}$ cells/well and treated with SiNPs $(12.5,25,50$ and $100 \mu \mathrm{g} / \mathrm{mL})$ with or without PJ34 $(10 \mu \mathrm{M})$, NAC $(5 \mathrm{mM}$, A7250, Sigma, USA), compound A1 $(10 \mu \mathrm{M})$, TPEN $(5 \mu \mathrm{M}$, P4413, Sigma, USA) and BAPTA-AM $(1 \mu \mathrm{M}$, A1076, Sigma, USA) for 24 or $48 \mathrm{~h}$. Cells were washed twice with PBS and CCK-8 was added to each well. After further incubated for $1.5 \mathrm{~h}$, the absorbance at $450 \mathrm{~nm}$ was evaluated using a microplate reader (Tecan Infinite M200, Switzerland). 


\section{Detection of intracellular ROS}

ROS was detected using DCFH-DA staining and fluorescence imaging. BEAS-2B cells were grown on glassbottom dishes (Cellvis, CA, USA) to $70 \%$ confluence, and treated with SiNPs $(100 \mu \mathrm{g} / \mathrm{mL})$ for $12 \mathrm{~h}$ in the presence or absence of NAC ( $5 \mathrm{mM})$, and SiNPs-calcined $(100 \mu \mathrm{g} / \mathrm{mL})$ at $600^{\circ} \mathrm{C}$. Thirty minutes prior to imaging, cells were fed with fetal bovine serum free RPMI-1640 loaded with DCFH-DA (10 $\mu$ M, S0033, Beyotime, Shanghai, China) in dark and kept in a $\mathrm{CO}_{2}$ incubator at $37^{\circ} \mathrm{C}$. Cells were washed twice with HBSS (\#14025092, Gibco, USA) and visualized under an Olympus FV1000 confocal microscope. Data were analyzed using ImageJ software. DCFH-DA intensity was analyzed by integrated intensity across the whole image divided by total cell number in the same mage using ImageJ.

\section{Quantitative RT-PCR}

Total RNA was isolated using a RNAiso Plus kit (9109, Takara, Shiga, Japan) and was reverse-transcribed to cDNA using a PrimeScript ${ }^{\mathrm{mm}}$ RT reagent Kit with gDNA Eraser (RR047A, Takara, Shiga, Japan), according to the manufacturer's instructions. The cDNA were stored at $-80^{\circ} \mathrm{C}$ until used. Quantitative PCR was performed using a SYBR Premix Ex Taq ${ }^{\mathrm{Tm}}$ II Kit (RR820A, Takara, Shiga, Japan) and a 7500 Fast Real-Time PCR System (Applied Biosystems, Thermo Fisher Scientific, USA). Relative mRNA expression was calculated using the $2^{-\triangle \Delta C T}$ method, and normalized to GAPDH. The primers for IL-1 $\beta$, IL-6, CXCL-1, CXCL-8 and GAPDH used are listed as follows:

IL-1 $\beta$-human.

Forward: 5' -AGCTGATGGCCCTAAACAGA-3'.

Reverse: $5^{\prime}$-TGGTGGTCGGAGATTCGTAG-3'.

IL-1 $\beta$-mouse.

Forward: 5' -TGGTGGTCGGAGATTCGTAG-3' .

Reverse: 5'-CTAATGGGAACGTCACACACCA-3'.

IL-6-human.

Forward: 5' -CCACTCACCTCTTCAGAACG-3' .

Reverse: 5'-CATCTTTGGAAGGTTCAGGTTG-3'.

IL-6-mouse.

Forward: 5' -CATCTTTGGAAGGTTCAGGTTG-3' .

Reverse: $\quad 5^{\prime}$-TTGTATCTCTGGAAGTTTCAGA

TTGTT-3'.

TNF- $\alpha$-human.

Forward: 5' -TAGCCCATGTTGTAGCAAACC-3'.

Reverse: 5'-ATGAGGTACAGGCCCTCTGAT-3'.

TNF- $\alpha$-mouse.

Forward: 5' -GCCACCACGCTCTTCTGTCTAC-3'. Reverse: 5'-GCCACCACGCTCTTCTGTCTAC-3'. CXCL-1-human.

Forward: 5' - CCAAACCGAAGTCATAGCCAC-3'. Reverse: 5' - TGCTCCCCTTGTTCAGTATCT-3'. CXCL-8-human.
Forward: 5' - ACTGAGAGTGATTGAGAGTGGAC-3' . Reverse: 5' - AACCCTCTGCACCCAGTTTTC-3'. GAPDH-human.

Forward: 5' -ACAGTCCATGCCATCACTG-3'. Reverse: 5'-AGTAGAGGCAGGGATGATG-3'. GAPDH-mouse.

Forward: 5' -AGTAGAGGCAGGGATGATG-3'. Reverse: 5'-AGTAGAGGCAGGGATGATG-3'.

\section{Elisa}

The levels of IL-1 $\beta$, IL-6, CXCL-1 and CXCL- 8 in culture medium were assessed using ELISA kits (ELHIL1 $\beta-1 / E L H-I L-6-1 / E L H-G R O \alpha-1 / E L H-I L 8-1, \quad$ Raybiotech, GA, USA) according to the manufacturer's recommendations. In the experiments testing the effects of inhibitors, cells were treated with PJ34 $(10 \mu \mathrm{M})$, compound $\mathrm{A} 1(10 \mu \mathrm{M})$ or MCC950 $(100 \mathrm{nM}) 30 \mathrm{~min}$ before and during subsequent exposure to SiNPs $(100 \mu \mathrm{g} / \mathrm{ml})$ for $24 \mathrm{~h}$.

\section{Western blotting}

BEAS-2B cell were lysed in RIPA lysis buffer (P0013B, Beyotime, Shanghai, China) containing PMSF (1 mM). After centrifugation at $20000 \times g$ for $10 \mathrm{~min}$, the supernatant was collected and its concentration was determined using an Enhanced BCA Protein Assay Kit (P0009, Beyotime, Shanghai, China). Forty micrograms of proteins were separated by SDS-PAGE using $8 \%$ gels for detecting TRPM2 and LAMP1, or $12 \%$ gels for SQSTM1, LC3B and Cathepsin-D. $\beta$-actin was used as the protein loading control. Proteins were transferred onto polyvinylidene fluoride (PVDF) membranes (Immobilon-P, Millipore, MA, USA), and blocked in 5\% skim milk in Tris-buffered saline containing $0.1 \%$ Tween 20 $(\mathrm{v} / \mathrm{v})$ (TBST) for $2 \mathrm{~h}$ at room temperature. The membranes were incubated with primary antibodies for TRPM2 (ab96785, 1:1000 dilution, Abcam, USA), LAMP1 (\#9091, 1:1000 dilution, CST, USA), SQSTM1 (PM045, 1:1000 dilution, MBL, Japan), LC3B (\#12741, 1: 1000 dilution, CST, USA), Cathepsin-D (ab75852, 1:1000 dilution, Abcam, USA), and $\beta$-actin (A5316, 1:5000 dilution, Sigma, USA) overnight at $4{ }^{\circ} \mathrm{C}$. After subjected to three 5-min washes in TBST, the membranes were incubated with secondary antibodies conjugated with various fluorophores (926-68,020, anti-mouse; 926-32,211, antirabbit; 1:5000 dilution, LI-COR, USA), and proteins were visualized and analyzed using a LI-COR Odyssey Infrared Fluorescent System.

\section{LysoTracker green staining}

BEAS-2B cells were seeded on glass-bottom dishes. After exposure to SiNPs $(100 \mu \mathrm{g} / \mathrm{mL})$ for $24 \mathrm{~h}$, the cells were washed twice with HBSS and incubated for $30 \mathrm{~min}$ with $1 \mathrm{~mL}$ of prewarmed HBSS containing LysoTracker 
Green DND-26 dye (200 nM, L7526, Invitrogen, USA) [27]. After washing with HBSS, cells were viewed and imaged using a confocal fluorescence microscope (Olympus FV1000, Tokyo, Japan). The number and size of lysosomes in each cell was analyzed using Image).

\section{Plasmids and transient transfection}

The mApple-LAMP1-pHluorin-N-8 construct was a gift from Dr. Michael Davidson (\#54918, Addgene, USA). BEAS-2B cells at $60 \%$ confluence were transiently transfected with mApple-LAMP1-pHluorin or RFP-LC3-GFP plasmids using Lipofectamine 2000 $(11,668,019$, Invitrogen, USA) according to the manufacturer's instructions. Transfected cells were cultured in glass-bottom dishes. For lysosome assay, BEAS-2B cells expressing mApple-LAMP1-pHluorin were treated with PJ34 or compound A1 (both at $10 \mu \mathrm{M}), 30 \mathrm{~min}$ prior to and during exposure to SiNPs $(100 \mu \mathrm{g} / \mathrm{mL})$ for $24 \mathrm{~h}$, and imaged under a confocal fluorescence microscope. For autophagy assay, BEAS-2B cells expressing RFP-LC3-GFP were treated with SiNPs $(100 \mu \mathrm{g} / \mathrm{mL})$ for $24 \mathrm{~h}$ in the presence or absence of PJ34 $(10 \mu \mathrm{M})$. Cells treated with $50 \mu \mathrm{M}$ CQ (C6628, Sigma, USA) for $3 \mathrm{~h}$ were used as a positive control. Images from at least three different fields per dish were captured using a confocal microscope. Cells were examined using ImageJ for lysosome function and autophagic flux. Normal lysosomes show red puncta, and impaired lysosomes show yellow puncta, and the ratio of red to yellow puncta in each cell was derived to indicate lysosome function. Autolysosomes show red puncta, and autophagosomes show yellow puncta. Autophagic flux was assessed by the ratio of autophagosomes to autolysosomes in each cell.

\section{Acridine orange staining}

Acridine orange (AO), a lysosomotropic weak base that accumulates in intracellular acidic compartments due to proton trapping, was used to measure the degradation function of lysosomes [77]. It is a metachromatic lysosomotropic dye that fluoresces red when accumulated at high concentrations in the lysosomes and green at low concentrations in the cytosol and the nucleus. Cells seeded on glass-bottom dishes were exposed to SiNPs $(100 \mu \mathrm{g} / \mathrm{mL})$ in the absence or presence of compound A1 $(10 \mu \mathrm{M})$, TPEN $(5 \mu \mathrm{M})$, or BAPTA-AM $(1 \mu \mathrm{M})$ for $24 \mathrm{~h}$, and stained with $5 \mu \mathrm{g} / \mathrm{mL}$ AO (A6014, Sigma, USA) at $37^{\circ} \mathrm{C}$ for $30 \mathrm{~min}$. After washing twice with PBS, cells were imaged under a confocal fluorescence microscope (Olympus FV1000, Tokyo, Japan) with excitation at $488 \mathrm{~nm}$ (green fluorescence) or $546 \mathrm{~nm}$ (red fluorescence).
Analysis of lysosomal degradation capacity

DQ-BSA, a BSA derivative with green fluorescence quenched after cleavage by proteolytic enzyme, was utilized to detect lysosomal degradation capacity. Cells seeded on glass-bottom dishes were incubated with $10 \mu \mathrm{g} / \mathrm{mL}$ DQ-BSA-Green (D12050, Invitrogn, USA) for $12 \mathrm{~h}\left(37^{\circ} \mathrm{C}, 5 \% \mathrm{CO}_{2}\right)$ and washed with $\mathrm{PBS}$ before exposed to SiNPs $(100 \mu \mathrm{g} / \mathrm{mL})$ in the absence or presence of PJ34 or compound A1 (both at $10 \mu \mathrm{M}$ ). Images were captured using a confocal microscope with excitation at $488 \mathrm{~nm}$. The degradation capacity was estimated by measuring the green fluorescence intensity using imageJ.

\section{Intracellular calcium measurement}

The effect of SiNPs on intracellular free $\mathrm{Ca}^{2+}$ concentration was determined by using Fluo-3/AM (F1242, Invitrogen, USA) following the manufacturer's instructions. In brief, BEAS-2B cells were seeded in 96-well plates (3603, Costar, USA) and incubated with Fluo-3/AM $(3.5 \mu \mathrm{M})$ at $37^{\circ} \mathrm{C}$ for $1 \mathrm{~h}$. The cells were washed with HBSS and incubated with PJ34 and compound A1 (both at $10 \mu \mathrm{M}) 30 \mathrm{~min}$ prior to addition of SiNPs $(100 \mu \mathrm{g} /$ $\mathrm{mL}$ ). Fluorescence was measured at $0.5,1,2,3 \mathrm{~h}$ in a SynergyMx M5 microplate reader (Molecular Devices, USA) with excitation at $488 \mathrm{~nm}$ and emission at $525 \mathrm{~nm}$. The intensity of samples was normalized to that of the control. Each group had 3 replicate wells and all procedures were performed in the dark.

\section{Statistical analysis}

Data were expressed as mean \pm standard deviation (SD) from at least three independent experiments. All the data shown in this study showed a normal distribution and therefore unpaired Student's $t$-test was used to compare two groups and one-way ANOVA with post hoc Bonferroni test to compare more than two groups, using SPSS 22.0. A $p$-value of less than 0.05 was considered statistically significant. All graphics were prepared using Prism 6 (GraphPad Software, La Jolla, CA, USA).

\section{Supplementary information}

Supplementary information accompanies this paper at https://doi.org/10. 1186/s12989-020-00353-3.

\footnotetext{
Additional file 1 : Figure $\mathbf{S 1}$ Characterization of SiNPs in suspension. A) The representative morphologies of SiNPs shown using transmission electron microscopy (TEM). Scale bar $=20 \mathrm{~nm}$. B) Size-distribution histograms obtained using Nano Measurer software. C) The surface area of SiNPs determined by the BET method. D) The hydrodynamic size, polydispersity index and zeta potential of SiNPs determined using DLS and Zetasizer Nano Series, respectively.

Additional file $\mathbf{2}$ : Figure $\mathbf{S} \mathbf{2}$ Inhibition of PARP and TRPM2 channel reduces SiNPs-induced cytokines and chemokines genernation in BEAS$2 B$ cells. IL-1 $\beta$ (A), IL-6 (B), CXCL-1 (C) and CXCL-8 (D). Cells were incubated with SiNPs $(100 \mu \mathrm{g} / \mathrm{mL})$ in the absence or presence of PJ34 or compound A1 (both at $10 \mu \mathrm{M}$ ). Data are presented as mean \pm SD from
} 
three independent experiments. ${ }^{*} P<0.05,{ }^{*} P<0.01$ compared with the control group. ${ }^{\#} P<0.05,{ }^{\# \#} P<0.01,{ }^{\# \# \#} P<0.001$ compared with SiNPstreated group.

Additional file 3 : Figure S3 Treatment with PJ34 has no effect on SiNPs-induced cytokines and chemokines generation in iBMDM cells. IL$1 \beta$ (A), IL-6 (B), and TNF-a (C). Cells were exposed to SiNPs $(100 \mu \mathrm{g} / \mathrm{mL})$ in the absence or presence of PJ34 $(10 \mu \mathrm{M})$. Data are presented as mean \pm SD from three independent experiments. ${ }^{* *} P<0.01$ compared with the control group.

Additional file 4 : Figure S4. Inhibition of NLRP3 inflammasome attenuates SiNPs-induced inflammation in BEAS-2B cells. Cells were coincubated with SiNPs $(100 \mathrm{\mu g} / \mathrm{mL})$ for $24 \mathrm{~h}$ in the absence or presence of MCC950 (100 nM). Data are presented as mean \pm SD from three independent experiments. ${ }^{*} P<0.05$, ${ }^{* * *} P<0.001$ compared to the control group. ${ }^{\# \#} P<0.01$ compared to SiNPs-treated group.

Additional file $\mathbf{5}$ : Figure $\mathbf{S 5}$. Autophagic flux regulates inflammatory responses in BEAS-2B cells. IL-1B (A) and IL-6 (B). BEAS-2B cells were treated with $50 \mu \mathrm{M}$ chloroquine (CQ) or $100 \mathrm{nM}$ rapamycin (RAPA) for $3 \mathrm{~h}$. Data are presented as mean \pm SD from three independent experiments. * $P<0.05$, ${ }^{* *} P<0.01,{ }^{* * *} P<0.001$ compared to the control group.

Additional file $\mathbf{6}$ : Figure $\mathbf{S 6}$. Analysis of inflammatory cells in the BALFs of WT and Trpm2 $2^{-1-}$ mice. The counts of total cells (A), macrophages (B), neutrophils (C), lymphocytes (D) in the BALFs from WT and Trpm $2^{-1-}$ mice after i.t instillation of SiNPs $(10 \mathrm{mg} / \mathrm{kg})$. Data are mean \pm SD from 8 mice. ${ }^{*} P<0.05$, ${ }^{* *} P<0.01,{ }^{* * *} P<0.001$ compared with the control group. ${ }^{\prime} P<0.05, \# P<0.01$ compared with the WT mice.

\section{Abbreviations}

NPs: Nanoparticles; SiNPs: Silica nanoparticles; PARP: poly (ADP-ribose) polymerase; ROS: Reactive oxygen species; TRPM2: Transient receptor potential melastatin 2; BALFs: Bronchoalveolar lavage fluids; DLS: Dynamic light scattering; TEM: Transmission electron microscopy; FTIR: Fourier transform infrared; LDH: Lactate dehydrogenase; IL: Interleukin; ELISA: Enzyme-linked immunosorbent assay; TNF-a: Tumor necrosis factor-a; H\&E: hematoxylin and eosin; RBCs: Red blood cells; NAC: N-acetyl-L-cysteine; LMP: Lysosomal membrane permeabilization; LAMP1: Lysosomal-associated membrane protein 1; CQ: Chloroquine; RAPA: Rapamycin; CTSD: Cathepsin-D; AO: Acridine orange; RT-PCR: Reversa transcription-polymerase chain reaction; TG: Thermogravimetric; EPR: Electron paramagnetic resonance; IARC: International Agency for Research on Cancer

\section{Acknowledgements}

The authors would like to acknowledge Prof Jeffrey Brinker (Department of Chemical and Nuclear Engineering, University of New Mexico) for kindly providing some advices on the chemical characterization of SiNPs, and the supporting from University of Leeds-Zhejiang University Strategic Collaboration Partnership Programme.

\section{Authors' contributions}

WY, PY and BD conceived, designed and directed the study. MW and JL performed the animal experiments. MW contributed to the cell viability assay, detection of intracellular ROS, western blotting analysis, quantitative RT-PCR. SD contributed to the chemical characterization of SiNPs. JL and XC performed the acridine orange staining and analysis of lysosomal degradation capacity. AS and XY performed the hemolysis assay. MW and JL collected and analyzed the data and drafted the paper. $X Z$ and $J L$ provided technical support and conceptual advice. WY, PY and BD participated in discussions, helped interpret the data, and revised the manuscript. LHJ provided technical support and conceptual advice, and revised the manuscript. All authors read and approved the final manuscript.

\section{Funding}

This work was supported by grants from the National Natural Science Foundation of China (31872796), National Science and Technology Major Projects for "Major New Drugs Innovation and Development" (2018ZX09711001-004-005), Zhejiang Provincial Natural Science Foundation (LR16H090001, LY19B020013), and 111 project, the Non-profit Central Research Institute Fund of Chinese Academy of Medical Sciences (2017PT31038, 2018PT31041).

\section{Availability of data and materials}

The datasets used and/or analyzed during this study are available from the corresponding authors on reasonable request.

\section{Ethics approval and consent to participate}

Animals were treated humanely and all experimental protocols were approved by the Committee on Animal Use and Care of Zhejiang University. All the methods in the present study were performed according to the approved guidelines.

\section{Consent for publication}

Not applicable.

\section{Competing interests}

The authors declare no conflict of interest.

\section{Author details}

${ }^{1}$ Department of Toxicology, and Department of Medical Oncology of Second Affiliated Hospital, Zhejiang University School of Medicine, Hangzhou, P. R. China. ${ }^{2}$ MOE Key Laboratory of Macromolecular Synthesis and Functionalization, Department of Polymer Science \& Engineering, Zhejiang University, Hangzhou, China. ${ }^{3}$ Department of Biophysics, and Department of Neurosurgery of the First Affiliated Hospital, Zhejiang University School of Medicine, Hangzhou, P. R. China. ${ }^{4}$ The Fourth Affiliated Hospital, Zhejiang University School of Medicine, Yiwu, P. R. China. ${ }^{5}$ Institute of Neuroscience, $\mathrm{NHC}$ and CAMS Key Laboratory of Medical Neurobiology, Zhejiang University School of Medicine, Hangzhou, P. R. China. ' Sino-UK Joint Laboratory of Brain Function and Injury and Department of Physiology and Neurobiology, Xinxiang Medical University, Xinxiang, P. R. China. ${ }^{7}$ School of Biomedical Sciences, Faculty of Biological Sciences, University of Leeds, Leeds LS2 9JT, UK.

Received: 18 November 2019 Accepted: 26 May 2020 Published online: 08 June 2020

\section{References}

1. Napierska D, Thomassen LC, Lison D, Martens JA, Hoet PH. The nanosilica hazard: another variable entity. Part Fibre Toxicol. 2010;7(1):39.

2. Hamilton RF Jr, Thakur SA, Holian A. Silica binding and toxicity in alveolar macrophages. Free Radic Biol Med. 2008;44(7):1246-58.

3. Tomonaga T, Izumi H, Yoshiura Y, Myojo T, Oyabu T, Lee BW, Okada T, Marui T, Wang KY, Kubo M, et al. Usefulness of myeloperoxidase as a biomarker for the ranking of pulmonary toxicity of nanomaterials. Part Fibre Toxicol. 2018;15(1):41.

4. Murugadoss S, Lison D, Godderis L, Van Den Brule S, Mast J, Brassinne F, Sebaihi N, Hoet PH. Toxicology of silica nanoparticles: an update. Arch Toxicol. 2017:91(9):2967-3010.

5. $\quad$ Yang H, Wu QY, Li MY, Lao CS, Zhang YJ. Pulmonary toxicity in rats caused by exposure to Intratracheal instillation of $\mathrm{SiO}_{2}$ nanoparticles. Biomed Environ Sci. 2017;30(4):264-79.

6. Zhao X, Wei S, Li Z, Lin C, Zhu Z, Sun D, Bai R, Qian J, Gao X, Chen G, et al. Autophagic flux blockage in alveolar epithelial cells is essential in silica nanoparticle-induced pulmonary fibrosis. Cell Death Dis. 2019;10(2):127.

7. Yang M, Jing L, Wang J, Yu Y, Cao L, Zhang L, Zhou X, Sun Z. Macrophages participate in local and systemic inflammation induced by amorphous silica nanoparticles through intratracheal instillation. Int J Nanomedicine. 2016;11: 6217-28.

8. Wang J, Yu Y, Lu K, Yang M, Li Y, Zhou X, Sun Z. Silica nanoparticles induce autophagy dysfunction via lysosomal impairment and inhibition of autophagosome degradation in hepatocytes. Int J Nanomedicine. 2017;12: 809-25.

9. Schutz I, Lopez-Hernandez T, Gao Q, Puchkov D, Jabs S, Nordmeyer D, Schmudde M, Ruhl E, Graf CM, Haucke V. Lysosomal dysfunction caused by cellular accumulation of silica nanoparticles. J Biol Chem. 2016;291(27): $14170-84$.

10. Liu N, Tang M. Toxic effects and involved molecular pathways of nanoparticles on cells and subcellular organelles. J Appl Toxicol. 2020;40(1): $16-36$.

11. Hornung $V$, Bauernfeind $F$, Halle A, Samstad EO, Kono H, Rock KL, Fitzgerald KA, Latz E. Silica crystals and aluminum salts activate the NALP3 
inflammasome through phagosomal destabilization. Nat Immunol. 2008;9(8): 847-56.

12. Li R, Ji Z, Qin H, Kang X, Sun B, Wang M, Chang CH, Wang X, Zhang H, Zou $H$, et al. Interference in autophagosome fusion by rare earth nanoparticles disrupts autophagic flux and regulation of an interleukin-1 beta producing inflammasome. ACS Nano. 2014;8(10):10280-92.

13. Popp L, Tran V, Patel R, Segatori L. Autophagic response to cellular exposure to titanium dioxide nanoparticles. Acta Biomater. 2018;79:354-63.

14. Brady OA, Martina JA, Puertollano R. Emerging roles for TFEB in the immune response and inflammation. Autophagy. 2018;14(2):181-9.

15. Fliegert R, Bauche A, Wolf Perez AM, Watt JM, Rozewitz MD, Winzer R, Janus M, Gu F, Rosche A, Harneit A, et al. 2'-Deoxyadenosine 5'-diphosphoribose is an endogenous TRPM2 superagonist. Nat Chem Biol. 2017;13(9):1036-44.

16. Yonezawa $R$, Yamamoto $S$, Takenaka M, Kage $Y$, Negoro T, Toda $T$, Ohbayashi M, Numata T, Nakano Y, Yamamoto T, et al. TRPM2 channels in alveolar epithelial cells mediate bleomycin-induced lung inflammation. Free Radic Biol Med. 2016:90:101-13.

17. Wyrsch P, Blenn C, Bader J, Althaus FR. Cell death and autophagy under oxidative stress: roles of poly (ADP-ribose) polymerases and $\mathrm{Ca}^{2+}$. Mol Cell Biol. 2012;32(17):3541-53.

18. Jiang Q, Gao Y, Wang C, Tao R, Wu Y, Zhan K, Liao M, Lu N, Lu Y, Wilcox CS, et al. Nitration of TRPM2 as a molecular switch induces autophagy during brain Pericyte injury. Antioxid Redox Signal. 2017;27(16):1297-316.

19. Yu P, Li J, Jiang J, Zhao Z, Hui Z, Zhang J, Zheng Y, Ling D, Wang L, Jiang $\mathrm{LH}$, et al. A dual role of transient receptor potential melastatin 2 channel in cytotoxicity induced by silica nanoparticles. Sci Rep. 2015;5:18171.

20. Zhang H, Dunphy DR, Jiang X, Meng H, Sun B, Tarn D, Xue M, Wang X, Lin $S$, Ji Z, et al. Processing pathway dependence of amorphous silica nanoparticle toxicity: colloidal vs pyrolytic. J Am Chem Soc. 2012;134(38): 15790-804.

21. Mossman BT. Introduction to serial reviews on the role of reactive oxygen and nitrogen species (ROS/RNS) in lung injury and diseases. Free Radic Biol Med. 2003;34(9):1115-6.

22. Sethi GS, Dharwal V, Naura AS. Poly (ADP-ribose)Polymerase-1 in lung inflammatory disorders: a review. Front Immunol. 2017;8:1172.

23. Zhang J, Qin X, Wang B, Xu G, Qin Z, Wang J, Wu L, Ju X, Bose DD, Qiu F, et al. Zinc oxide nanoparticles harness autophagy to induce cell death in lung epithelial cells. Cell Death Dis. 2017;8(7):e2954.

24. Kuroda E, Ozasa K, Temizoz B, Ohata K, Koo CX, Kanuma T, Kusakabe T, Kobari S, Horie M, Morimoto Y, et al. Inhaled fine particles induce alveolar macrophage death and interleukin-1alpha release to promote inducible bronchus-associated lymphoid tissue formation. Immunity. 2016;45(6):1299310.

25. Zhang Y, Mao P, Li G, Hu J, Yu Y, An T. Delineation of 3D dose-time-toxicity in human pulmonary epithelial Beas-2B cells induced by decabromodiphenyl ether (BDE209). Environ Pollut. 2018;243(Pt A):661-9.

26. Eaton JW, Qian M. Molecular bases of cellular iron toxicity. Free Radic Biol Med. 2002;32(9):833-40.

27. Lin YX, Wang Y, Qiao SL, An HW, Zhang RX, Qiao ZY, Rajapaksha RP, Wang $\mathrm{L}$, Wang $\mathrm{H}$. pH-sensitive polymeric nanoparticles modulate Autophagic effect via lysosome impairment. Small. 2016;12(21):2921-31.

28. Cheng XT, Xie YX, Zhou B, Huang N, Farfel-Becker T, Sheng ZH. Revisiting LAMP1 as a marker for degradative autophagy-lysosomal organelles in the nervous system. Autophagy. 2018;14(8):1472-4.

29. Ma X, Wu Y, Jin S, Tian Y, Zhang X, Zhao Y, Yu L, Liang XJ. Gold nanoparticles induce autophagosome accumulation through sizedependent nanoparticle uptake and lysosome impairment. ACS Nano. 2011; 5(11):8629-39.

30. Miesenbock G, De Angelis DA, Rothman JE. Visualizing secretion and synaptic transmission with $\mathrm{pH}$-sensitive green fluorescent proteins. Nature. 1998;394(6689):192-5.

31. Vazquez CL, Colombo Ml. Assays to assess autophagy induction and fusion of autophagic vacuoles with a degradative compartment, using monodansylcadaverine (MDC) and DQ-BSA. Methods Enzymol. 2009:452:8595.

32. Song XB, Liu G, Liu F, Yan ZG, Wang ZY, Liu ZP, Wang L. Autophagy blockade and lysosomal membrane permeabilization contribute to leadinduced nephrotoxicity in primary rat proximal tubular cells. Cell Death Dis. 2017:8(6):e2863.

33. Orr ME, Oddo S. Autophagic/lysosomal dysfunction in Alzheimer's disease. Alzheimers Res Ther. 2013;5(5):53.
34. Mizushima N, Yoshimori T, Levine B. Methods in mammalian autophagy research. Cell. 2010;140(3):313-26.

35. Bjorkoy G, Lamark T, Brech A, Outzen H, Perander M, Overvatn A, Stenmark $H$, Johansen T. p62/SQSTM1 forms protein aggregates degraded by autophagy and has a protective effect on huntingtin-induced cell death. $J$ Cell Biol. 2005:171(4):603-14.

36. Jiang P, Mizushima N. LC3- and p62-based biochemical methods for the analysis of autophagy progression in mammalian cells. Methods. 2015;75: 13-8.

37. Manna S, Howitz WJ, Oldenhuis NJ, Eldredge AC, Shen J, Nihesh FN, Lodoen MB, Guan Z, Esser-Kahn AP. Immunomodulation of the NLRP3 Inflammasome through structure-based activator design and functional regulation via Lysosomal rupture. ACS Cent Sci. 2018;4(8):982-95.

38. Sun B, Wang X, Ji Z, Li R, Xia T. NLRP3 inflammasome activation induced by engineered nanomaterials. Small. 2013;9(9-10):1595-607.

39. Coll RC, Robertson AA, Chae JJ, Higgins SC, Munoz-Planillo R, Inserra MC, Vetter I, Dungan LS, Monks BG, Stutz A, et al. A small-molecule inhibitor of the NLRP3 inflammasome for the treatment of inflammatory diseases. Nat Med. 2015:21(3):248-55.

40. Racanelli AC, Kikkers SA, Choi AMK, Cloonan SM. Autophagy and inflammation in chronic respiratory disease. Autophagy. 2018;14(2):221-32.

41. Liu Y, Yu H, Zhang X, Wang Y, Song Z, Zhao J, Shi H, Li R, Wang Y, Zhang LW. The protective role of autophagy in nephrotoxicity induced by bismuth nanoparticles through AMPK/mTOR pathway. Nanotoxicology. 2018;12(6): 586-601.

42. Caiafa P, Guastafierro T, Zampieri M. Epigenetics: poly (ADP-ribosyl) ation of PARP-1 regulates genomic methylation patterns. FASEB J. 2009;23(3):672-8.

43. Esposito E, Cuzzocrea S. Superoxide, NO, peroxynitrite and PARP in circulatory shock and inflammation. Front Biosci (Landmark Ed). 2009;14: 263-96.

44. Zhang H, Liu H, Luo X, Wang Y, Liu Y, Jin H, Liu Z, Yang W, Yu P, Zhang L, et al. Design, synthesis and biological activities of 2,3-dihydroquinazolin-4(1H)-one derivatives as TRPM2 inhibitors. Eur J Med Chem. 2018;152:235-52.

45. Li F, Abuarab N, Sivaprasadarao A. Reciprocal regulation of actin cytoskeleton remodelling and cell migration by $\mathrm{Ca}^{2+}$ and $\mathrm{Zn}^{2+}$ : role of TRPM2 channels. J Cell Sci. 2016;129(10):2016-29.

46. Ye M, Yang W, Ainscough JF, Hu XP, Li X, Sedo A, Zhang XH, Zhang X, Chen $Z$. Li XM, et al. TRPM2 channel deficiency prevents delayed cytosolic $\mathrm{Zn}^{2+}$ accumulation and CA1 pyramidal neuronal death after transient global ischemia. Cell Death Dis. 2014:5:e1541.

47. Frohlich E, Meindl C, Roblegg E, Ebner B, Absenger M, Pieber TR. Action of polystyrene nanoparticles of different sizes on lysosomal function and integrity. Part Fibre Toxicol. 2012;9:26.

48. Ghiazza M, Polimeni M, Fenoglio I, Gazzano E, Ghigo D, Fubini B. Does vitreous silica contradict the toxicity of the crystalline silica paradigm? Chem Res Toxicol. 2010;23(3):620-9.

49. Maurer-Jones MA, Lin YS, Haynes CL. Functional assessment of metal oxide nanoparticle toxicity in immune cells. ACS Nano. 2010;4(6):3363-73.

50. Yu T, Malugin A, Ghandehari H. Impact of silica nanoparticle design on cellular toxicity and hemolytic activity. ACS Nano. 2011;5(7):5717-28.

51. He Q, Zhang Z, Gao Y, Shi J, Li Y. Intracellular localization and cytotoxicity of spherical mesoporous silica nano- and microparticles. Small. 2009:5(23):2722-9.

52. Song $Y, L i X, D u X$. Exposure to nanoparticles is related to pleural effusion, pulmonary fibrosis and granuloma. Eur Respir J. 2009;34(3):559-67.

53. You R, Ho YS, Hung CH, Liu Y, Huang CX, Chan HN, Ho SL, Lui SY, Li HW, Chang RC. Silica nanoparticles induce neurodegeneration-like changes in behavior, neuropathology, and affect synapse through MAPK activation. Part Fibre Toxicol. 2018;15(1):28

54. Cho WS, Choi M, Han BS, Cho M, Oh J, Park K, Kim SJ, Kim SH, Jeong J. Inflammatory mediators induced by intratracheal instillation of ultrafine amorphous silica particles. Toxicol Lett. 2007;175(1-3):24-33.

55. Rubio L, Pyrgiotakis G, Beltran-Huarac J, Zhang Y, Gaurav J, Deloid G, Spyrogianni A, Sarosiek KA, Bello D, Demokritou P. Safer-by-design flamesprayed silicon dioxide nanoparticles: the role of silanol content on ROS generation, surface activity and cytotoxicity. Part Fibre Toxicol. 2019;16(1):40.

56. Deretic $V$, Levine B. Autophagy balances inflammation in innate immunity. Autophagy. 2018;14(2):243-51.

57. Yu Y, Duan J, Yu Y, Li Y, Liu X, Zhou X, Ho KF, Tian L, Sun Z. Silica nanoparticles induce autophagy and autophagic cell death in HepG2 cells triggered by reactive oxygen species. J Hazard Mater. 2014;270:176-86. 
58. Duan J, Yu Y, Yu Y, Li Y, Wang J, Geng W, Jiang L, Li Q, Zhou X, Sun Z. Silica nanoparticles induce autophagy and endothelial dysfunction via the PI3K Akt/mTOR signaling pathway. Int J Nanomedicine. 2014;9:5131-41.

59. Wang J, Li Y, Duan J, Yang M, Yu Y, Feng L, Yang X, Zhou X, Zhao Z, Sun Z. Silica nanoparticles induce autophagosome accumulation via activation of the EIF2AK3 and ATF6 UPR pathways in hepatocytes. Autophagy. 2018;14(7):1185-200.

60. Jiang X, Tang Q, Zhang J, Wang H, Bai L, Meng P, Qin X, Xu G, Bose DD, Wang $B$, et al. Autophagy-dependent release of zinc ions is critical for acute lung injury triggered by zinc oxide nanoparticles. Nanotoxicology. 2018; 12(9):1068-91.

61. Cohignac V, Landry MJ, Ridoux A, Pinault M, Annangi B, Gerdil A, HerlinBoime N, Mayne M, Haruta M, Codogno P, et al. Carbon nanotubes, but not spherical nanoparticles, block autophagy by a shape-related targeting of lysosomes in murine macrophages. Autophagy. 2018;14(8):1323-34.

62. Sumoza-Toledo A, Lange I, Cortado H, Bhagat H, Mori Y, Fleig A, Penner R, Partida-Sanchez S. Dendritic cell maturation and chemotaxis is regulated by TRPM2-mediated lysosomal $\mathrm{Ca}^{2+}$ release. FASEB J. 2011;25(10):3529-42.

63. Knowles H, Heizer JW, Li Y, Chapman K, Ogden CA, Andreasen K, Shapland E, Kucera G, Mogan J, Humann J, et al. Transient receptor potential Melastatin 2 (TRPM2) ion channel is required for innate immunity against listeria monocytogenes. P Natl Acad Sci USA. 2011;108(28):11578-83.

64. Ham HY, Hong CW, Lee SN, Kwon MS, Kim YJ, Song DK. Sulfur mustard primes human neutrophils for increased degranulation and stimulates cytokine release via TRPM2/p38 MAPK signaling. Toxicol Appl Pharmacol. 2012;258(1):82-8.

65. Hiroi T, Wajima T, Negoro T, Ishii M, Nakano Y, Kiuchi Y, Mori Y, Shimizu S. Neutrophil TRPM2 channels are implicated in the exacerbation of myocardial ischaemia/reperfusion injury. Cardiovasc Res. 2013;97(2):271-81.

66. Zheng Q, Tan Q, Ren Y, Reinach PS, Li L, Ge C, Qu J, Chen W. Hyperosmotic stress-induced TRPM2 channel activation stimulates NLRP3 Inflammasome activity in primary human corneal epithelial cells. Invest Ophthalmol Vis Sci. 2018:59(8):3259-68.

67. Yoon $\mathrm{JH}$, Jeong $\mathrm{SH}$, Hong $\mathrm{JH}$. The effect of therapeutic blockades of dust particles-induced $\mathrm{Ca}^{2+}$ signaling and Proinflammatory cytokine IL-8 in human bronchial epithelial cells. Mediat Inflamm. 2015;2015:843024.

68. Yamamoto S, Shimizu S, Kiyonaka S, Takahashi N, Wajima T, Hara Y, Negoro T, Hiroi T, Kiuchi Y, Okada T, et al. TRPM2-mediated $\mathrm{Ca}^{2+}$ influx induces chemokine production in monocytes that aggravates inflammatory neutrophil infiltration. Nat Med. 2008;14(7):738-47.

69. Di A, Gao XP, Qian F, Kawamura T, Han J, Hecquet C, Ye RD, Vogel SM, Malik AB. The redox-sensitive cation channel TRPM2 modulates phagocyte ROS production and inflammation. Nat Immunol. 2011;13(1):29-34.

70. Peiro T, Patel DF, Akthar S, Gregory LG, Pyle CJ, Harker JA, Birrell MA, Lloyd CM, Snelgrove RJ. Neutrophils drive alveolar macrophage IL-1 beta release during respiratory viral infection. Thorax. 2018;73(6):546-56.

71. Qian X, Numata T, Zhang K, Li C, Hou J, Mori Y, Fang X. Transient receptor potential melastatin 2 protects mice against polymicrobial sepsis by enhancing bacterial clearance. Anesthesiology. 2014;121(2):336-51.

72. Abuarab N, Munsey TS, Jiang LH, Li J, Sivaprasadarao A. High glucoseinduced ROS activates TRPM2 to trigger lysosomal membrane permeabilization and $\mathrm{Zn}^{2+}$-mediated mitochondrial fission. Sci Signal. 2017; 10(490):eaal4161.

73. Li X, Jiang LH. A critical role of the transient receptor potential melastatin 2 channel in a positive feedback mechanism for reactive oxygen speciesinduced delayed cell death. J Cell Physiol. 2019;234(4):3647-60.

74. Zou J, Ainscough JF, Yang W, Sedo A, Yu SP, Mei ZZ, Sivaprasadarao A, Beech DJ, Jiang LH. A differential role of macrophage TRPM2 channels in $\mathrm{Ca}^{2+}$ signaling and cell death in early responses to $\mathrm{H}_{2} \mathrm{O}_{2}$. Am J Physiol Cell Physiol. 2013;305(1):C61-9.

75. Shi J, Zhao Y, Wang K, Shi X, Wang Y, Huang H, Zhuang Y, Cai T, Wang F, Shao F. Cleavage of GSDMD by inflammatory caspases determines pyroptotic cell death. Nature. 2015;526(7575):660-5.

76. Xu H, Yang J, Gao W, Li L, Li P, Zhang L, Gong YN, Peng X, Xi JJ, Chen S, et al. Innate immune sensing of bacterial modifications of rho GTPases by the Pyrin inflammasome. Nature. 2014;513(7517):237-41.

77. Boya P, Kroemer G. Lysosomal membrane permeabilization in cell death. Oncogene. 2008;27(50):6434-51.

\section{Publisher's Note}

Springer Nature remains neutral with regard to jurisdictional claims in published maps and institutional affiliations.

\section{Ready to submit your research? Choose BMC and benefit from:}

- fast, convenient online submission

- thorough peer review by experienced researchers in your field

- rapid publication on acceptance

- support for research data, including large and complex data types

- gold Open Access which fosters wider collaboration and increased citations

- maximum visibility for your research: over $100 \mathrm{M}$ website views per year

At BMC, research is always in progress.

Learn more biomedcentral.com/submissions 